\title{
Antibacterial Coatings Based on Chitosan for Pharmaceutical and Biomedical Applications
}

\author{
Juliana Miguel Vaz ${ }^{\mathrm{a}, \mathrm{b}}$, Daniele Pezzoli ${ }^{\mathrm{a}}$, Pascale Chevallier ${ }^{\mathrm{a}}$, Clayton Souza Campelo ${ }^{\mathrm{a}}$, Gabriele Candiani ${ }^{\mathrm{c}}$ \\ and, Diego Mantovani*, a
}

\begin{abstract}
${ }^{a}$ Laboratory for Biomaterials and Bioengineering, CRC-I, Department of Mining, Metallurgical and Materials Engineering and CHU de Quebec Research Centre, Laval University, Quebec City (QC), Canada; ${ }^{b}$ Laboratory of Engineering and Products Chemistry, Department of Materials and Engineering and Bioprocess, School of Chemical Engineering, University of Campinas, Campinas (SP), Brazil; " Department of Chemistry, Materials and Chemical Engineering "Giulio Natta”, Politecnico di Milano, Milan, Italy
\end{abstract}

\section{A R T I C L E H IS T O R Y}

Received: January 23, 2018

Accepted: February 15, 2018

DOI:

$10.2174 / 1381612824666180219143900$
Abstract: The risk of bacterial colonization of abiotic surfaces of biomedical devices poses important challenges for the pharmaceutical and biomaterials science fields. In this scenario, antibacterial coatings have been developed, using a number of different molecules and materials. Among them, chitosan is a non-cytotoxic, biocompatible biopolymer with an inherent antimicrobial activity that has been already used in a wide variety of healthcare and industrial applications. Herein, chitosan-based antibacterial coatings are critically surveyed, with a special emphasis on their production methods, pharmaceutical and biomedical applications, along with their pros and cons, and finally highlighting the key challenges to be faced and future perspectives in this field.

Keywords: Chitosan, antibacterial coatings, biomedical devices, biofilm, contact-killing surfaces, biocompatibility, physisorption, grafting

\section{INTRODUCTION}

Bacterial contamination of material surfaces represents an extremely serious issue in biomedical device development owing to the associated health, social and economic expenses [1]. In this context, antibacterial coatings are an increasingly studied area of research. The tremendous progress in material design and processing, and surface modification techniques have in fact prompted the development of surfaces that are able to prevent bacterial adhesion and proliferation and eventually biofilm formation, thus minimizing the risks of biomedical device-related infections.

Several strategies for the design of antibacterial coatings have been reported, such as antimicrobial agent release, contact-killing and adhesion resistance/bacteria-repelling [2], each aiming to overcome the limitations of the customary administration of antibiotics.

Chitosan (Fig. 1) is a natural-derived polymer (i.e., a biopolymer) with acknowledged antimicrobial properties that, due to its many favorable biological properties, such as high biocompatibility, low immunogenicity and allergenicity, ease of processing, represents a very attractive material for the development of surface coatings with inherent antibacterial activity and that can be further loaded with other, more selective antimicrobials [3].

Up to now a plethora of applications in the biomedical field has been proposed for chitosan-based antibacterial coatings, ranging from wound healing [4] to intraocular lenses [5], from dental implants to orthopedic prostheses [6--15], from sutures [16] to catheters [17].

This survey aims to review the most striking developments in chitosan-based antibacterial surface coatings for pharmaceutical

*Address correspondence to this author at the Department of Mining, Metallurgical and Materials Engineering, Faculty of Science and Engineering, Laval University, Pavillon Pouliot, room 1745-E, G1V 0A6, Quebec City (QC), Canada; Tel/Fax: +1-418-656-2131 ext. 6270,+1-418-656-5343; E-mail: Diego.Mantovani@gmn.ulaval.ca

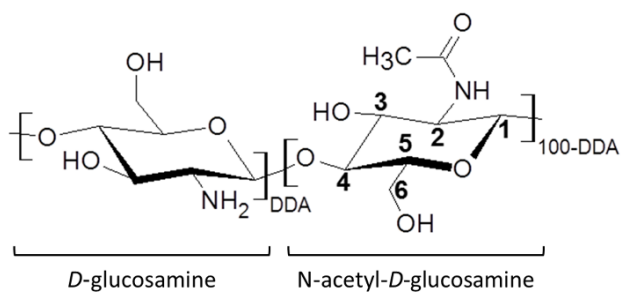

Fig. (1). Chemical structure of chitosan and denomination of carbon position (C1-C6). The N-acetyl- $D$-glucosamine and $D$-glucosamine units are indicated; DDA indicates the deacetylation degree.

and biomedical applications. After pointing out in brief the issue of microbial contamination of abiotic surfaces and the main strategies adopted for the development of antibacterial coatings, the foremost properties, and applications of chitosan and chitosan derivatives will be thoroughly described. Finally, the techniques developed for the production of chitosan-based antibacterial coatings will be reviewed and critically discussed.

\section{BACTERIAL CONTAMINATION: A CHALLENGE FOR THE BIOMEDICAL FIELD}

In this section, we will discuss the concerns related to bacterial contamination relevant to the biomedical field. The main mechanisms of bacterial colonization on material surfaces and the several factors related to this phenomenon will be described, and the socioeconomic impact of healthcare-associated infections (HCAIs) examined.

\subsection{Some Basics on Bacteria}

Human body is host to trillions of microbes ordinarily establishing beneficial relations. In fact, a physiologically stable equilibrium exists between tissues/organs and guest microorganisms, such as the resident intestinal and oral flora, the skin bacteria, etc. [18--20]. 
There are two common ways to classify bacteria based on phenotypic features (Fig. 2). The first one relies on their shape, which depends on the types of cytoskeletal proteins and their organization: bacteria can be spherical (cocci, e.g., Staphylococcus aureus), cylindrical (bacilli, e.g., Escherichia coli), spiral-shaped (spirilla, e.g., Spirillum volutans), and comma-shaped (vibrio, e.g., Vibrio cholera).

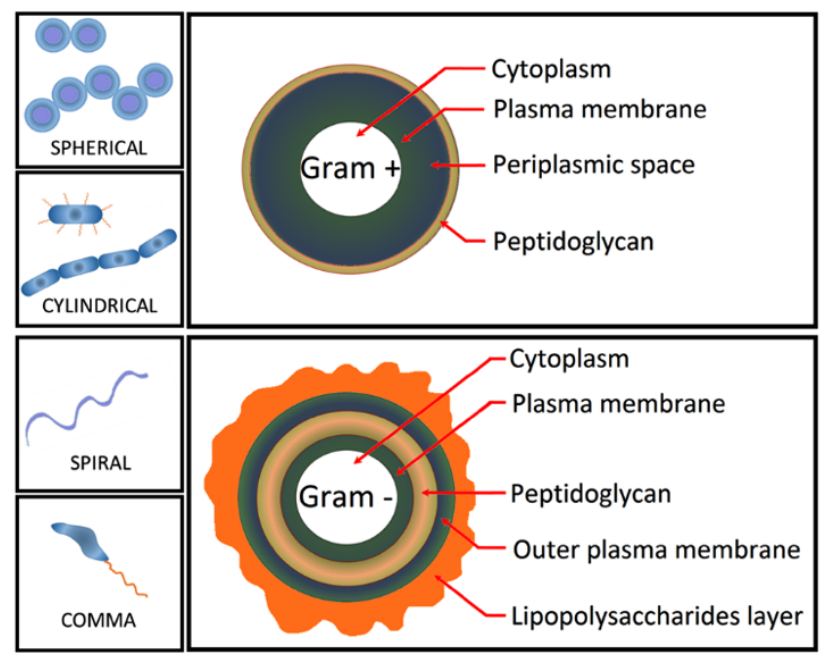

Fig. (2). Representation of bacteria classification by shape (spherical cocci, cylindrical bacilli, spiral-shaped spirilla and comma-shaped vibrio).

Besides, based on the cell wall composition and structure, bacteria can be categorized as Gram-positive and Gram-negative. Gram-positive bacteria, such as Staphylococcus aureus, have an outer cell wall composed of several thick layers of peptidoglycans. Gram-negative bacteria, such as Pseudomonas aeruginosa and Escherichia coli, present a more complex cell wall composed of a single thin layer of peptidoglycans sandwiched between the inner (cytoplasmic) cell membrane and an outer membrane rich in lipopolysaccharides (LPS) and lipoproteins [21].

Bacteria can exist as planktonic cells (i.e., isolated, free-floating cells) or sessile aggregates (i.e., attached to a surface or living within a biofilm). Planktonic cells are responsible for the rapid proliferation and spread of microorganisms to new sites, while sessile cells characterize localized bacterial colonization and are often related to chronic pathological conditions [22, 23]. Worthy of note is the ability of bacteria to switch back and forth between these two states.

\subsection{Mechanism of Bacterial Colonization of Surfaces}

In general, the bacterial colonization process of a surface begins with the reversible adhesion of planktonic bacteria on the surface (Fig. 3).

Bacteria approach surface through Brownian motion or in directed mode, by means of flagella, the lash-like appendages of locomotion. When the microorganism and the surface reach a critical proximity (in the range of $\approx 1 \mathrm{~nm}$ ), its adhesion depends on the balance of attractive and repulsive forces between their surfaces. At this stage, non-specific physicochemical interactions are involved, including hydrogen bonds, electrostatic, van der Waals and hydrophobic interactions. On the other hand, adhesins, unique proteins present on the bacterial surface, mediate the adhesion to the substrate $[22,24,25]$. When the bacterial density increases, by proliferation or recruitment of other cells, the quorum sensing process stimulates the proliferation and the exopolysaccharide matrix (EPS or slime) production, leading to the formation of the biofilm

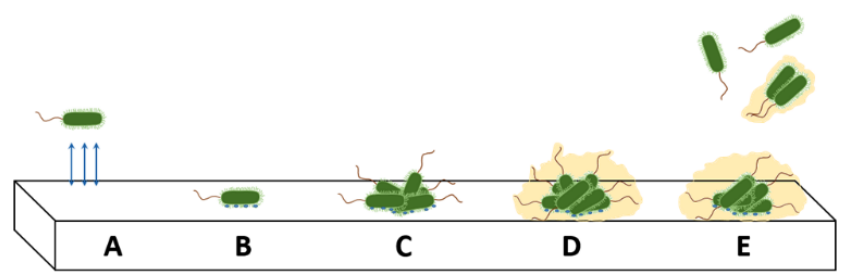

Fig. (3). The model of stages of bacterial colonization surfaces. The process begins through (A) physicochemical, non-specific and labile interactions followed by (B) stable attachment to the surface mediated by adhesins. (C) The bacteria density increases and (D) the colony produces an exopolysaccharide matrix (EPS) finally forming the biofilm. When the environment is no more favorable, (E) bacteria detach to colonize new sites.

(Fig. 3). The biofilm is a viscous layer, forming mushroom-like structures, composed of a variable fraction of $5-35 \%$ of bacteria, of the total biofilm volume, surrounded by EPS, permeated by water channels for delivery of nutrients, and removal of metabolites. This structure constitutes a protected mode of growth for bacteria populations, allowing their survival in hostile environments [22, 26, 27]. Finally, in certain conditions, such as when the environment is no more favorable or because of a cellular programming for virulence, the detachment of planktonic cells or cell groups bound by the EPS occurs. This phenomenon leads to biofilm spreading and to the colonization of new sites [22, 26--28].

When considering devices implanted into the body, the interactions and reversible/stable adhesion between bacteria and the abiotic surface may be influenced by the implantation site. In fact, several molecules present in physiological fluids such as proteins (e.g., albumin, immunoglobulins (Ig), fibrinogen, fibronectin, etc.), proteoglycans, polysaccharides and lipids interact nonspecifically with the surface through electrostatic, Van der Waals and hydrophobic forces leading to reversible adsorption on the material and to the formation of the so-called conditioning film that modifies the physicochemical properties of the surface and thus possibly affecting bacterial adhesion and the following colonization process [22, 29--31]. The bacterial adhesion and biofilm formation on a material surface is a complex phenomenon, being influenced by three main factors: the characteristics of the bacteria strain, the physical, chemical and biological properties of the microenvironment, and the type of substrate, and each one of these factors is strictly related to many sub-parameters [30, 32, 33], as summarized in Fig. 4.

Once formed, biofilms are often resistant to the popular cleaning methods, sterilization as well as to antibiotics. These features make them very difficult to eradicate and, when associated with implanted biomedical devices, they can cause severe health problems [1].

\subsection{Bacterial Contamination: A Socio-economic Problem}

Despite the considerable progress in the treatment of microbial infections, in fact, bacterial contaminations in healthcare environments can cause serious health concerns and this is particularly relevant when considering the surface of a biomedical device that must be implanted or used in direct contact with body tissues [34-36].

In healthcare environments, pathogenic bacteria usually arise from an infected host or directly from the environment, through common vehicles, such as contaminated air or water (Fig. 5). In this regard, the contamination of biomedical devices and surgical tools is considered a major issue in medical interventions [1, 32, 36, 37].

HCAIs are non pre-existential infections developed after a patient is exposed to healthcare facilities or biomedical devices contaminated by pathogenic microorganisms. HCAIs are considered as 


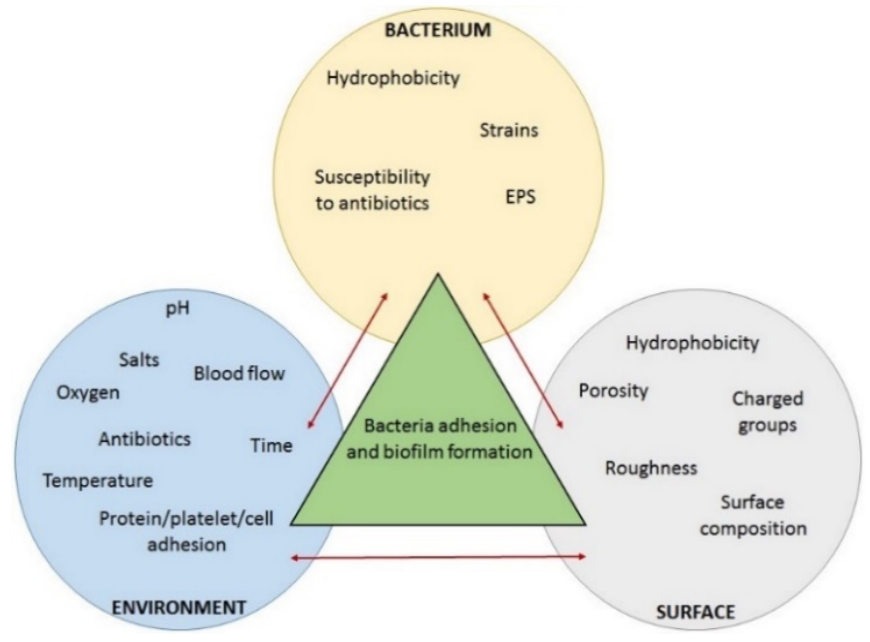

Fig. (4). Parameters and sub-parameters related to bacterial adhesion and biofilm formation on a biomedical device.

very serious safety threats in healthcare today because of their high incidence and of their related social and economic expenses.

In fact, HCAIs can dramatically prolong the hospitalization period, affect patients after discharge and, the most important, when associated with surgical interventions and to the use of invasive biomedical devices they can lead to implant failure and reintervention, and if not properly treated, even to death.

It is estimated that, worldwide, HCAIs will be responsible for 10 million deaths in 2050 [38]. Currently, in the USA alone, the contamination caused by microorganisms is responsible for around 722, 000 HCAIs, resulting in nearly 75, 000 deaths, and the associated yearly costs are estimated between $\$ 4.5$ and $\$ 11$ billion. In Canada, every year 220, 000 people develop HCAIs, 8, 000-12, 000 patients die and more than $\$ 1$ billion is spent. The estimated incidence in Europe is 4.1 million affected patients yearly, with a burden of 37, 000 direct deaths and 117,000 indirectly related deaths each year. The situation is much worse in Latin American and African countries due to poor infrastructures and inadequate hygiene conditions $[2,39,40]$.

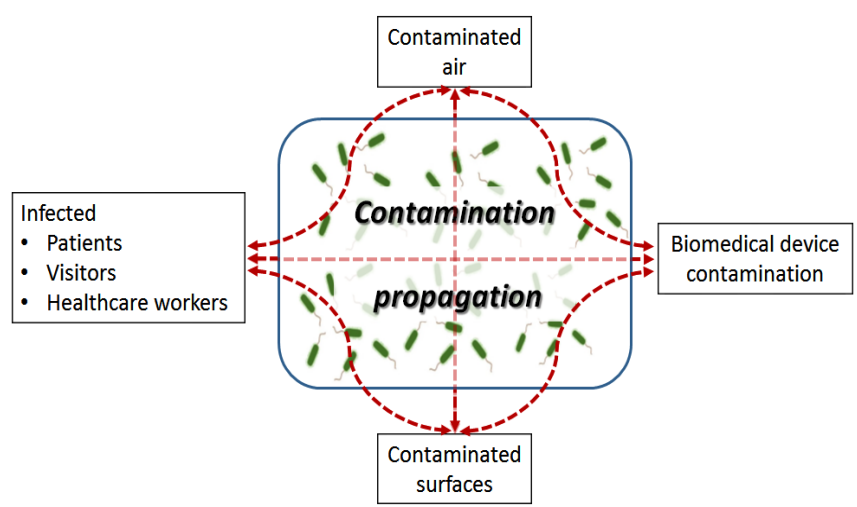

Fig. (5). Routes of the bacterial contamination spread in healthcare environments. The contamination can be spread by infected patients, visitors, and healthcare workers, through contaminated surfaces or air.

Another serious problem related to HCAIs is the increased and widespread antibiotic resistance of microorganisms. HCAIs caused by methicillin-resistant Staphylococcus aureus (MRSA), vancomycin-resistant Enterococcus (VRE), and Clostridium difficile are becoming progressively more contagious and hard-to-treat [41].
In order to minimize the cases of HCAI, hand washing is the main strategy that is applied by healthcare employers worldwide. Although this is crucial to control and to prevent infections, it does not avoid the problem of cross-contamination. For example, an employee that has cleaned his hands can contaminate a patient after touching a contaminated surface.

In addition, regular surface cleaning and hygiene procedures in hospitals remain less effective when a bacterial biofilm is already formed. Therefore, the prevention of surface bacterial contamination is a great challenge in the biomedical field [34], particularly relevant when considering implantable biomedical devices [42] as evidenced by Tab. 1 that shows a general retrospect about bacterial infection incidence connected to some of the most commonly employed biomedical devices.

On this ground, the development of inherently antibacterial surfaces is a very promising approach to prevent HCAIs. The practical strategies proposed by investigators to this purpose are described in the section herein below.

\section{ANTIBACTERIAL SURFACES: STRATEGIES AND DE- SIGNS}

As mentioned in Section 2, once formed on the surface of materials, biofilms are very difficult to strip out. The development of effective antibacterial surfaces has thus become a major challenge in biomaterial design and antibacterial coatings have become a very active field of research, strongly stimulated by the increasing urgency of identifying viable alternatives to the prophylactic administration of antibiotics [2].

An extensive literature survey points out three main strategies for the development of antibacterial surfaces, each of them with some pros and cons (Table 2), that are antibacterial agent release, contact-killing, and adhesion resistance/bacteria-repelling.

Such lines of research that aim to enhance the antimicrobial properties of a surface can be implemented individually or synergistically $[2,18,21,35,43,44]$. However, regardless of the strategy and surface design, common features for antibacterial surfaces are required, such as biocompatibility, non-cytotoxicity, and reproducible production methods [44].
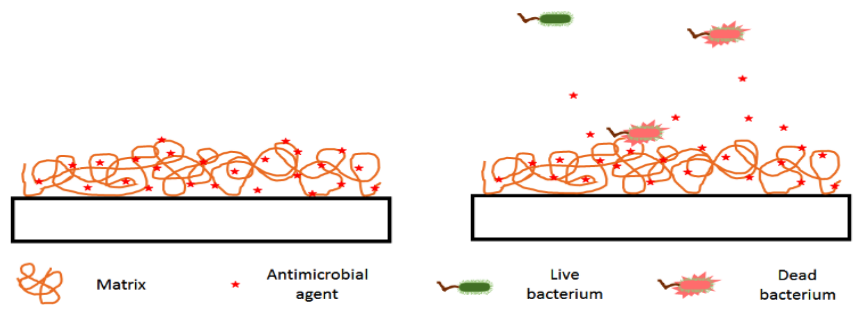

Fig. (6). Agent release strategy for the development of antibacterial surfaces.

\subsection{Antibacterial Agent Release}

Antimicrobial agents such as metal ions, peptides, and antibiotics can be incorporated within and/or grafted on the surface of biomaterials to provide them with antimicrobial properties [56]. The material composition should favor the release of these compounds in a controlled fashion allowing antimicrobials to kill both adherent and adjacent planktonic bacteria with a long-lasting effect (Fig. 6) $[18,44,43]$.

The release of incorporated antibacterial agents can be achieved by simple diffusion from the implantation site to the surrounding aqueous medium, by material degradation, or hydrolysis of covalent bonds $[2,44]$.

This general approach has some drawbacks (Table 2). Indeed, as it is difficult to predict the type and number of infecting bacteria at the implantation site, the load and the selection of the appropriate 
Table 1. Most common device-related pathogens and infection incidence.

\begin{tabular}{|c|c|c|c|}
\hline Device & Infection agent & Infection incidence & Reference \\
\hline Breast implants & S. aureus, CoNS*, S. pyogenes, Propionibacterium spp. & $0.8-1.7 \%$ & {$[45]$} \\
\hline Cardiac pacemakers & S. aureus, CoNS, Streptococcus spp, Candida spp. & $0.1-7 \%$ & {$[46]$} \\
\hline Central venous catheter & CoNS, S. aureus, Enterococcus spp., Candida spp., K. pneumoniae & $2-10 \%$ & [47] \\
\hline Cochlear implants & S. aureus, P. aeruginosa, H. influenzae, Streptococcus spp. & $1.7-3.3 \%$ & {$[48]$} \\
\hline Contact lenses & S. aureus, $P$. aeruginosa, Bacillus species & $0.3-5.2 \%$ & [49] \\
\hline Coronary stents & S. aureus, CoNS, $P$. aeruginosa, Candida spp. & $0.4 \%$ & {$[50,51]$} \\
\hline Dental implants & Streptococcus spp., Actinomyces spp., Porphyromonas spp., Prevotella spp. & $5-10 \%$ & {$[22,30]$} \\
\hline Fracture fixation devices & S. aureus, CoNS, Propionibacterium spp., Streptococcus spp., Corynebacterium spp. & $5-10 \%$ & {$[22]$} \\
\hline Hip/knee implants & S. aureus, CoNS, Streptococcus spp., Enterobacteriaceae & $0.5-4 \%$ & {$[22,47]$} \\
\hline Intraocular lenses & S. epidermidis & $0.01-0.3 \%$ & {$[52]$} \\
\hline Mechanical heart valve & S. aureus, CoNS, Streptococcus spp., Enterococcus spp. & $1-3 \%$ & {$[22]$} \\
\hline Penile implants & Staphylococcus spp., Pseudomonas spp., CoNS, Enterobacter spp. & $1-3 \%$ & [47] \\
\hline Sutures & S. aureus, $P$. aeruginosa, S. epidermidis, $\mathrm{CoNS}$ & $2-5 \%$ & {$[53,54]$} \\
\hline Urinary catheter & E. coli, Enterococcus spp & $10-30 \%$ & {$[55]$} \\
\hline
\end{tabular}

* CoNS coagulase-negative staphylococi

antimicrobial agent is challenging. The load may be too low to allow it to diffuse to the surroundings at the effective concentration, thus failing in its proper function.

If the agent is an antibiotic, it can face the problem of the host developing sensitivity to it and it can be inefficient toward antibiotic-resistant bacteria [57]. Furthermore, the lifetime of the antibacterial activity is limited by the antimicrobial agent reservoir (Table 2).

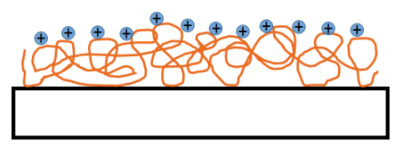

8 Matrix $\rightarrow \quad \begin{aligned} & \text { Positive } \\ & \text { charge }\end{aligned}$

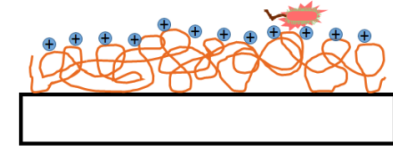

$\sim \underset{\text { Lacterium }}{\text { Live }}$
Fig. (7). Contact-killing strategy for the development of antibacterial surfaces.

\subsection{Contact-Killing}

The contact-killing approach aims to eliminate or, at least, to blunt the proliferation of microorganisms adhering to the material surface via the covalent tethering of antimicrobials through polymeric spacers (Fig. 7) $[18,21,35,44]$ that permit the penetration of the biocides into the cell wall $[58,59]$ and consequently lead to bacterial death.

Due to the net negative surface charge that bacteria typically display [60], the most effective compounds for contact-killing coatings are cationic chemicals (quaternary ammonium compounds, chitosan, antimicrobial cationic peptides, etc.) or enzymes, such as lysozyme and other proteases [2,61].
Differently from the antibacterial release, in the contact-killing approach, the antimicrobial agent does not exhaust its effect over time, retaining its activity for a long time. However, its range of action is restricted to the area of the device that has been tethered and, when in contact with biological fluids, nonspecific protein adsorption (fouling) impairs contact-killing activity (Table 2).

\subsection{Adhesion Resistance/Bacteria-repelling}

Anti-adhesive surfaces aim to avoid the early attachment of microorganisms to the material, thus finally preventing the formation of stable biofilms $[18,35,44,62]$, by means of different surface modification strategies (Fig. 8).

One of the approaches is to functionalize surfaces with molecules that can resist protein adsorption, such as polyethylene glycol (PEG) and zwitterions, or with superhydrophobic coatings (e.g., chitosan-based hydrophobic nanoparticles) [63], that demonstrated important anti-adhesion properties.

Even though stability concerns are often raised, these are generally considered as the standard approaches for the production of bacteria-repelling coatings. Despite evidence of the efficiency of the modified surface to prevent or limit bacterial adhesion, the main problem is related to the inability of such coatings to kill bacteria if the adhesion has already taken place (Table 2) [22].

Among the different design strategies developed for the production of antibacterial surfaces for biomedical applications, chitosanbased coatings represent a versatile, safe and promising approach due to the ease of processability and functionalization of chitosan, its inherent antibacterial activity and to its many other favorable properties.

In the following sections, after summarizing the main physicochemical and biological properties, and the many applications of chitosan and its derivatives, the techniques developed for the production of antibacterial chitosan coatings are reviewed in detail, with special emphasis on their advantages, drawbacks and on their range of pharmaceutical and biomedical applications. 
Table 2. Main advantages and disadvantages of the three strategies for the development of antibacterial surfaces.

\begin{tabular}{|c|c|c|}
\hline Strategy & Advantages & Disadvantages \\
\hline \hline Antibacterial \\
agent release & $\begin{array}{c}\text { Extensive action, possi- } \\
\text { bility to deliver a high } \\
\text { amount of antibacterial } \\
\text { agent }\end{array}$ & $\begin{array}{c}\text { Effect of bacterial inhibi- } \\
\text { tion temporary limited } \\
\text { by the reserve of antibac- } \\
\text { terial agents } \\
\text { Possible toxicity of the } \\
\text { biocidal agent }\end{array}$ \\
$\begin{array}{c}\text { Localized action, without } \\
\text { exceeding systemic toxic- } \\
\text { ity limits }\end{array}$ & $\begin{array}{c}\text { Possible induction of } \\
\text { bacterial resistance }\end{array}$ \\
\hline $\begin{array}{c}\text { Contact- } \\
\text { killing }\end{array}$ & $\begin{array}{c}\text { Potential long-term func- } \\
\text { tionality }\end{array}$ & $\begin{array}{c}\text { Action restricted to the } \\
\text { area of the modified } \\
\text { surface }\end{array}$ \\
& $\begin{array}{c}\text { Loss of activity in con- } \\
\text { tact with body fluids due } \\
\text { to protein fouling }\end{array}$ \\
\hline $\begin{array}{c}\text { Adhesion } \\
\text { resis- } \\
\text { tance/bacteria } \\
\text {-repelling }\end{array}$ & $\begin{array}{c}\text { Non-cytotoxic mecha- } \\
\text { nisms } \\
\text { prevented at the first step } \\
\text { of contamination }\end{array}$ & $\begin{array}{c}\text { Action restricted to the } \\
\text { functionalized surface } \\
\text { No bacterial killing }\end{array}$ \\
\hline
\end{tabular}

\section{CHITOSAN: A PECULIAR ECLECTIC MATERIAL}

Due to its chemical structure, especially to the presence of amino groups in its saccharide chain, chitosan is a versatile biopolymer very interesting for many biomedical applications. In this section, the sources of chitosan, the production process, its physicochemical and biological properties are described, with a special focus on the biomedical and pharmaceutical fields.

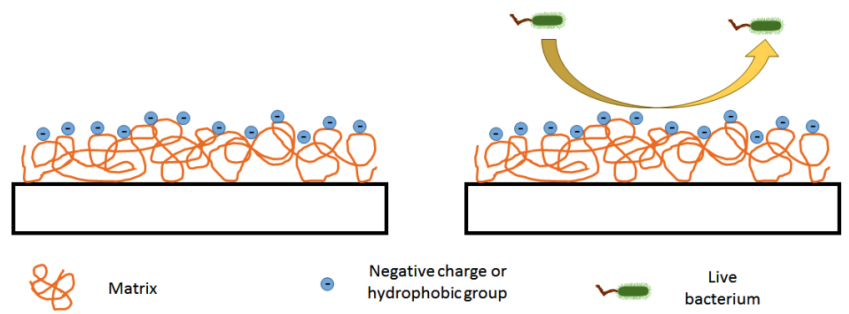

Fig. (8). Adhesion resistance/bacteria-repelling strategy for the development of antibacterial surfaces.

\subsection{History, Source, and Production}

Chitosan is a semi-natural polymer derived from chitin, the second most abundant natural polymer after cellulose and, excluding proteins, the natural compound with the largest nitrogen content [64]. Historically, chitin and chitosan appeared for the first time in the world research context in 1811 with H. Branconnot. This French professor treated mushrooms with an alkali solution and obtained a white fibroid residue that he called fungine. Branconnot believed that this material was a cellulose derivative $[65,66]$. In 1823 , A. Odier obtained a similar substance from the elytra of beetles and called it "chitin", based on Greek etymology, which means "A Coat Of Mail". In 1843, J.L. Lassaigne demonstrated that chitin composition displays nitrogen, in contrast with cellulose. In 1859,
C. Rouget boiled chitin in a concentrated alkali solution and rendered it soluble in organic acids. This chitin derivative was named "chitosan" only in 1894 by Hoppe-Seyler [65, 67]. However, it was only in the 1950's that the chemical structure of chitosan, featuring deacetylated residues, was defined.

The chitosan sources, which depend on the chitin source, are various and are summarized in Table $\mathbf{3}$.

Table 3. Sources and content of chitin in the nature.

\begin{tabular}{|c|c|c|c|c|c|}
\hline Sea animals & $\begin{array}{c}\text { Chitin } \\
\%\end{array}$ & Arthropods & $\begin{array}{c}\text { Chitin } \\
\%\end{array}$ & $\begin{array}{c}\text { Micro- } \\
\text { organisms }\end{array}$ & $\begin{array}{c}\text { Chitin } \\
\%\end{array}$ \\
\hline Annelida & \multirow{3}{*}{$20-38$} & Scorpions & \multirow{11}{*}{$20-60$} & Green algae & \multirow{11}{*}{ trace -45} \\
\hline Archiannelida & & Locusts & & & \\
\hline $\begin{array}{c}\text { Chaetopoda } \\
\text { Hirudinea }\end{array}$ & & Flies & & Brown algae & \\
\hline Mollusca & \multirow{4}{*}{$3-26$} & Spiders & & Yeast ( $\beta$-type) & \\
\hline \multirow{3}{*}{$\begin{array}{c}\text { Polyplacophora } \\
\text { Gastropoda } \\
\text { Scaphopoda } \\
\text { Cephalopoda }\end{array}$} & & Butterflies & & Chytridiaceae & \\
\hline & & Beetles & & Ascomydes & \\
\hline & & Mosquitos & & Blastocladiaceae & \\
\hline Cnidaria & \multirow[b]{2}{*}{$3-30$} & \multirow[b]{2}{*}{$\begin{array}{l}\text { Silkworm } \\
\text { chrysalis }\end{array}$} & & Fungi & \\
\hline $\begin{array}{c}\text { Hydrozoa } \\
\text { Scyphozoa } \\
\text { Anthozoa }\end{array}$ & & & & $\begin{array}{c}\text { Ascomycetes } \\
\text { Basidiomycetes } \\
\text { Phycomycetes }\end{array}$ & \\
\hline Crustaceans & \multirow[b]{2}{*}{$58-85$} & Ants & & \multirow[b]{2}{*}{$\begin{array}{l}\text { Mycelia penicil- } \\
\text { lium }\end{array}$} & \\
\hline $\begin{array}{c}\text { Lobster, crab, } \\
\text { shrimp, krill }\end{array}$ & & Cockroaches & & & \\
\hline
\end{tabular}

They are mainly divided into the following categories: sea animals, arthropods, algae, and fungi. Indeed, chitin is found in the cell wall of fungi belonging to Zygomycetes, in the green algae Chlorella Spirulina, in yeast, in radulae of mollusks as well as in exoskeleton of arthropods [68,69]. Nowadays, the main commercial production of chitosan, $10^{9}-10^{10}$ tons per year, is based on crustacean shells, due to their high content and ready availability. Chitosan market size was valued over $\$ 1.52$ billion in 2015 and is forecast to experience gains exceeding $16 \%$ compound average growth rate between 2016 and 2024 .

The industry frequently uses as raw material crustacean shell wastes, coming from byproducts of the seafood industries. Thus, this process is ecological-friendly and economically viable. The chitosan fabrication process used is a multi-step procedure:

- Chitin extraction: chitin is bound to proteins and mineral salts, thus, to recover the polysaccharides, a deproteinization step with alkali treatment at high temperature, and a demineralization step, in diluted chloride acid solution, are first performed.

- Bleaching process: to remove coloration from pigments present in the isolated chitin, oxidizing agents such as $\mathrm{KMnO}_{4}$, $\mathrm{H}_{2} \mathrm{O}_{2}$ and hypochlorite solution or solvent extraction are carried out.

- Deacetylation: the common procedure is the addition of sodium hydroxide solution at $40-50 \%(\mathrm{w} / \mathrm{v}$ in water), under stirring at high temperature ranging from 80 to $150^{\circ} \mathrm{C}$ for several hours. 
- Neutralization and purification: the previous basic solution is neutralized, and then chitosan purification is performed by solvatation/precipitation and filtration.

However, the properties of obtained chitosan in terms of purity, viscosity, degree of deacetylation, molecular weight (Mw) and polymorphous structure vary considerably with the process parameters such as temperature, reaction time, products used for deproteinization, demineralization, neutralization, and the purification steps.

\subsection{Physicochemical Properties of Chitosan}

The presence of primary amino groups in the chitosan structure differentiates it from chitin and gives to this polymer many peculiar properties. At acidic $\mathrm{pH}$, chitosan is a polycation with a linear chain consisting of $\mathrm{N}$-acetyl- $D$-glucosamine and $D$-glucosamine units linked by $\beta(1 \rightarrow 4)$ glycosidic bonds (Fig. 1).

Depending on the source and on the chitin extraction process, it is possible to produce chitosan with different ratios of $D$ glucosamine units over the total number of units per chain [70]. This ratio is called degree of deacetylation (DDA) that is usually between 60 and $95 \%$. The $\mathrm{Mw}$, instead, can range from five to 8 , $000 \mathrm{kDa}$, meaning from oligomers to very high $\mathrm{Mw}$ polymers. These two chemical properties are key parameters, influencing the distribution and amount of protonated amine moieties $\left(-\mathrm{NH}_{3}{ }^{+}\right)$in the chitosan chain. Indeed, $\mathrm{N}$-acetyl- $D$-glucosamine units affect the intrinsic viscosity and solubility of chitosan in aqueous solutions, and influence also the biodegradability and biocompatibility behaviors, the antibacterial activity, and many other properties, as summarized in Table 4 [70--72].

Table 4. Relationships between chitosan structural parameters (DDA and Mw) and its properties.

\begin{tabular}{|c|c|c|}
\hline \multirow{2}{*}{ Property } & \multicolumn{2}{|c|}{ Structural features } \\
\cline { 2 - 3 } & DDA & Mw \\
\hline \hline Physicochemical & & \\
\hline Solubility & Increase & Decrease \\
\hline Viscosity & Increase & Increase \\
\hline Crystallinity & Increase & Decrease \\
\hline Biological & & \\
\hline Biodegradability & Increase & Increase \\
\hline Biocompatibility & Increase & Increase \\
\hline Antimicrobial & Increase & Decrease \\
\hline
\end{tabular}

The crystallinity of chitosan is another key parameter that influences the biodegradability and its biological properties [73]. Higher DDA leads to greater crystallinity, which reaches the maximum when chitosan is fully deacetylated. On the other hand, crystallinity increases while decreasing the Mw [74].

A large number of analytical tools have been used to quantify these important structural features. The DDA can be evaluated by different spectroscopic techniques such as FTIR, UV, NMR, but also by conventional titration methods, equilibrium dye adsorption, elemental analysis, acid degradation coupling with HPLC, and thermal analysis. The Mw and its distribution are usually assessed by light scattering spectrophotometry, gel permeation chromatography and viscosimetry [64, 75--77].

Chitosan is poorly soluble/insoluble in (neutral) water, in alkaline medium and even in organic solvents. The $\mathrm{pH}$-dependent solu- bility of chitosan relies on its amino groups, which become protonated upon dissolution at $\mathrm{pH} \leq 6.5(\mathrm{pKa} \sim 6.3)$ to form cationic amino moieties, increasing intermolecular electric repulsion and resulting in a soluble polycation [70, 76, 78, 79]. Chitosan forms viscous solutions with pseudoplastic and viscoelastic properties, which are affected by DDA, Mw, concentration, type of solvent, $\mathrm{pH}$, ionic strength, and temperature $[71,76,80]$.

\subsection{Biological Properties of Chitosan}

Biocompatibility and biodegradability are important properties for applications in the pharmaceutical and biomaterial fields. In a general way, biomaterials produced with chitosan are well tolerated by living tissues, including skin, ocular membranes, bones as well as the nasal epithelium, and this is an important feature for a wide range of biomedical applications such as tissue engineering (e.g., bone, cartilage, cardiac, nerve, etc.), wound healing, and delivery systems (e.g., drug, proteins, peptides, antibiotics, etc.). In vivo toxicity studies, with chitosan, demonstrated its safety profile in terms of inertness and low toxicity for mammalian cells [81]. However, the purity degree of chitosan and its origin should be carefully checked as they may have some dramatic toxic effects (residual byproducts from the extraction procedure and traces of proteins from seafood) [71].

Chitosan has been reported as highly biodegradable because the break of glycosidic bonds can be easily achieved through a chemical or an enzymatic hydrolysis. This characteristic is crucial for drug delivery systems and tissue regeneration applications [82]. Chemical biodegradation refers to chitosan hydrolysis in acidic gastric milieu [83--85], whereas the enzymatic hydrolysis occurs by means of some enzymes such as lysozyme, which is found in mucosal surfaces, and chitinases, which is produced by the intestinal flora. The biodegradation of chitosan induces its depolymerization, and this, in turn, leads to the production of non-toxic oligosaccharides. This process is of key importance in regard to biomedical applications as such short oligosaccharides can be easily processed by regular metabolic pathways or excreted by renal clearance due to their size [84]. The chitosan biodegradation is related to its crystallinity degree, $\mathrm{Mw}$ and DDA: when chitosan crystallinity decreases, its biodegradation rate increases $[69,86]$. Besides, it can be assumed that smaller chitosan chains will be more rapidly degraded than chitosan with higher Mw [69].

Interestingly, chitosan displays useful mucoadhesive properties which are directly related to the DDA. Indeed, free amines from chitosan interact with the mucoadhesive membranes, made of a negatively charged glycoprotein called mucin [69, 87]. Therefore, the higher the DDA of chitosan, the greater the number of cationic charges carried, the stronger the interaction with anionic mucous membranes [88]. The interaction of the polycationic chitosan with the negatively charged cell membranes gives also rise to very interesting biological properties, such as hemostatic and analgesic effects. In this regard, the interaction of red blood cells, as well as platelets, with chitosan allows to speed up clot formation and hemostasis $[89,90]$, thus taking part in the coagulation and cicatrization process [91-93]. In the same matter, the analgesic effects of chitosan can be ascribed to the proton release by the cationic $D$ glucosamine residues in the area of inflammation [64].

Despite its non-cytotoxicity towards mammalian cells, chitosan has a wide spectrum of antimicrobial activity against fungi, Gram-positive and Gram-negative bacteria, and yeasts [94]. The mechanism of antimicrobial activity of chitosan is not completely known but several factors can influence it. Studies evaluating the antimicrobial activity of chitosan against different groups of microorganisms suggested that three main mechanisms of inhibition of microbial growth are involved $[95,96]$. The first and basic mechanism proposed relies on the cationic amino groups of chitosan that increase the permeability of negatively charged outer cellular layer, causing disruption and release of intracellular components (Fig. 
9A). Two other synergist mechanisms have been also identified: the inhibition of intracellular enzymes activity through the chelation of metals (Fig. 9B) and cytoplasmic DNA/mRNA complexation causing the inhibition of protein syntheses (Fig. 9C) [97, 98].

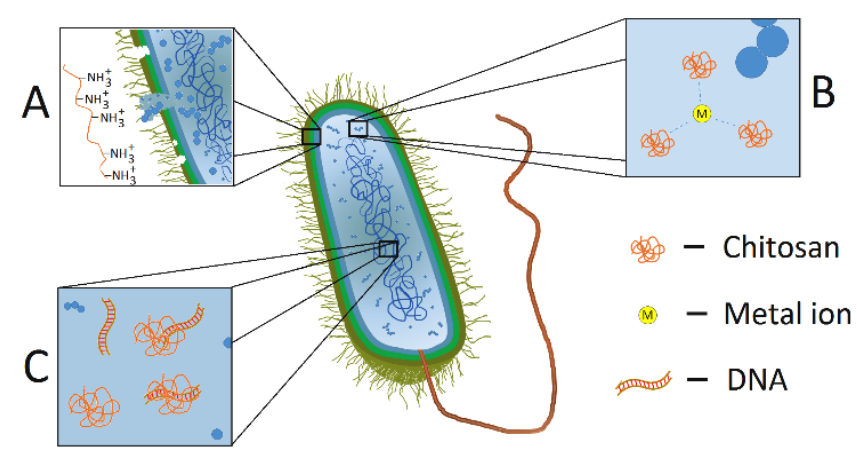

Fig. (9). Mechanisms of antibacterial action of chitosan: (A) cell wall charge disruption; (B) chelation of metals in trace; (C) complexation with DNA.

The antimicrobial activity of chitosan is influenced by its Mw. Low Mw chains were found more effective than longer ones, probably due to the higher mobility of small chains that can better penetrate the bacterial membrane $[3,69,99]$. In the same way, chitosan with high DDA and thus with highly cationic character, are more effective than those with a low DDA in terms of bacterial growth inhibition. Taken together, the antimicrobial activity of chitosan is due to the presence of protonated amino groups. In this regard, the $\mathrm{pH}$ thus strongly affects the antibacterial effectiveness of chitosan: the lower the $\mathrm{pH}$ (below the $\mathrm{pKa}$ value of $\approx 6.3$ ), the higher the antibacterial activity displayed by the aminopolysaccharide $[75,88,91,92,100,101]$.

\subsection{Immunogenicity, Allergenicity, and Genotoxicity of Chito- san}

Chitosan has been tested for safety and toxicity in a number of animal species, and by various routes of administration [102]. In this regard, Kitozyme and Primex Corporations have compiled comprehensive information as part of self-certifications to support a "generally recognized as safe" (GRAS) status as it has been recently and comprehensively reviewed by some authors [85, 103]. Overall, chitosan is widely regarded as being a non-toxic, biologically compatible polymer [104] and it is approved in Japan, Italy, and Finland for dietary applications [105] and it has been FDA approved for use in wound dressings [106].

\subsubsection{Immunogenicity and Antigenicity}

While immunogenicity is the ability of a particular substance, such as an antigen or epitope, to provoke a humoral and/or cellmediated immune response in the body of a human or animal, antigenicity is the capacity of some (bio)chemical factors, such as antigens or haptens, to be specifically recognized and bind T cell receptors or antibodies (IgG-binding) that are the products of adaptive immunity. Antigenicity was more commonly used in the past to refer to what is now known as immunogenicity, and the two are still often used interchangeably. The use of chitosan for pharmaceutical and medical applications requires highly purified GMP-grade material comprising carbohydrate containing little or no residual protein and chitosan-based products should comply with appropriate pharmacopoeial tests [102]. Since proteins are significantly more immunogenic than polysaccharides, purified chitosan is considered non-immunogenic and thus non-antigenic. On the other hand, chitosan has been shown to be involved in the production of IgM by the immune system in response to antigens. It stimulates in vitro IgM production but not that of IgG or IgA by HB4GS cells and human lymphocytes [107].

\subsubsection{Allergenicity}

Allergenicity is defined as the capacity of a given substance to elicit an IgE immune response upon animal or human exposure. Allergenicity is thus the potential of a material to cause sensitization and allergic reactions and is mediated through immunological mechanisms such as IgE antibody binding. Because some individuals are allergic to shellfish, some scientists have been prompted to investigate the presumed relationship between allergy and the presence of chitin in shellfish. It is worthy of note that isolated chitin is a biopolymer deeply different from that present in vivo, that is part of a complex structure with other inorganic and organic and components responsible for its allergenic potential. Instead, isolated, pure and ultrapure chitin and chitosan, are plain polysaccharides devoid of any residual proteins [108]. In this regard, a number of researchers have demonstrated the absence of any allergic response in subjects with shellfish allergy following oral challenge with shellfish-derived glucosamine [109, 110]. Further evidence on the anallergic properties of chitosan comes from the absence of allergic reactions, or any other adverse event, following the use of chitosan dressings, even in people allergic to shellfish [111].

\subsubsection{Genotoxicity}

Genotoxicity describes the property of chemical agents that damages the genetic information within a cell causing mutations, which may lead to cancer. The antigenotoxic activity of chitosan, assessed using the sister chromatid exchange assay following adsorption of different mutagens [112] showed that this biopolymer did reduce the genotoxicity of such chemicals, suggesting that it may play a protective role against environmental mutagens [113].

\subsection{Chitosan Modifications}

Chitosan reactive groups are readily subjected to chemical derivatization, to allow chitosan new functionalities and properties, as described in Table $\mathbf{5}$.

In fact, the deacetylation process gives to chitosan a new reactive functional group when compared with chitin: a primary amine at the $\mathrm{C}_{2}$ position. This amine and the primary and secondary hydroxyl groups at the $\mathrm{C}_{3}$ and $\mathrm{C}_{6}$ positions, respectively, are responsible for one of the most important features of chitosan: the ease of chemical modification under mild conditions. Such modifications are also used to provide chitosan, and chitosan-derivatives, with new mechanical and physicochemical properties: for instance, the solubility of chitosan at neutral $\mathrm{pH}$ has been improved by tethering water soluble, hydrophilic moieties to it [134], or its mechanical behavior has been heightened by controlled acetylation $[64,68,70$, $71,135]$.

\subsection{Chitosan applications}

The study and use of chitosan and of its derivatives have been constantly growing over the last four decades, as demonstrated by the steep increase in the number of papers indexed in Scopus database from 1975 (16 documents) to 2016 (5, 045 documents) related to chitosan and its derivatives. The peculiar chemical and biological properties of chitosan, together with the possibility to process it in multiple forms (powders, solutions, gels, sponges, beads, fibers, scaffolds, nanoparticles, films, porous and dense membranes) [89, 136--142], in fact have opened the way towards a number of applications in different fields, such as cosmetics, pharmaceutical, medical, agricultural, water treatment, food, and textiles, as summarized in Table 6.

This review focuses on chitosan-based antibacterial coatings for biomedical applications. The main applications of chitosan and its derivatives in cosmetics and in pharmaceutical and biomedical fields are summarized hereinafter in brief. 
Table 5. Some typical modifications of chitosan.

\begin{tabular}{|c|c|c|}
\hline Modification & Function & Reference \\
\hline Methylpyrrolidinone chitosan & $\begin{array}{l}\text { Hydrophilic chitosan- } \\
\text { caffolds for bone regen- } \\
\text { eration }\end{array}$ & {$[114]$} \\
\hline $\begin{array}{l}\text { 2-N-/6-O-/2-N, 6-O-sulfated } \\
\text { chitosan }\end{array}$ & $\begin{array}{l}\text { Enhance the activity of } \\
\text { Bone morphogenetic } \\
\text { protein-2 }\end{array}$ & [115] \\
\hline $\mathrm{N}, \mathrm{N}, \mathrm{N}$-trimethyl chitosan & Antibacterial activity & {$[116]$} \\
\hline Sulfonated chitosan & Hemocompatibility & [89] \\
\hline Chitosan-g-PVA & Hemocompatibility & {$[117]$} \\
\hline N-hexanoyl chitosan & Hemocompatibility & {$[118]$} \\
\hline $\mathrm{N}, \mathrm{O}-/ \mathrm{N}$-succinyl chitosan & Hemocompatibility & [119] \\
\hline Chitosan-g-PEG-folate & Gene carrier & {$[120]$} \\
\hline $\begin{array}{l}\text { O- } / \mathrm{N}, \mathrm{O}-\text { carboxymethyl chi- } \\
\text { tosan }\end{array}$ & Antibacterial activity & [121] \\
\hline \multirow{3}{*}{ Phosphorylcholine-chitosan } & $\begin{array}{l}\text { Drug delivery / gene } \\
\text { therapy }\end{array}$ & {$[122]$} \\
\hline & $\begin{array}{l}\text { Nanocarriers with pro- } \\
\text { tein-repelling proteins }\end{array}$ & [123] \\
\hline & $\begin{array}{l}\text { Substrate for endothelial } \\
\text { progenitor cells culture }\end{array}$ & {$[124]$} \\
\hline O-carboxymethyl chitosan & Hemocompatibility & {$[125]$} \\
\hline O-stearoyl chitosan & Hemocompatibility & {$[126]$} \\
\hline Chitosan-g-PEG & Antibacterial activity & {$[127]$} \\
\hline Chitosan-g-caffeic acid & Antioxidant activity & {$[128]$} \\
\hline Chitosan-g-lysozyme & Antibacterial activity & {$[61]$} \\
\hline 6-O-/3, 6-O-sulfated chitosan & Hemocompatibility & [129] \\
\hline N-octyl-O-sulfate chitosan & Drug carrier & {$[130]$} \\
\hline $\begin{array}{c}\text { Chitosan-g-poly(glycidyl } \\
\text { methacrylate) }\end{array}$ & Drug delivery & {$[131]$} \\
\hline $\begin{array}{l}\text { Chitosan-g-poly(2-(furan-2- } \\
\text { carbonyl)-acrylonitrile) }\end{array}$ & Antibacterial activity & {$[132]$} \\
\hline Chitosan-g-imidazole & Bone regeneration & [133] \\
\hline
\end{tabular}

\subsubsection{Pharmaceutical Applications -- Drug Delivery}

There are many examples in the literature about the use of chitosan and its derivatives as pharmaceutical products, for example in drug delivery [3].

Chitosan is commonly used as an excipient in tablet formulations for oral medication. In fact, viscous high $\mathrm{Mw}$ chitosan can delay the release of the active component, thus prolonging the duration of drug activity and improving the therapeutic efficiency and reducing the side effects related to high peak doses [151].
Table 6. Main applications of chitosan and derivatives in different fields.

\begin{tabular}{|c|c|c|}
\hline Field & Applications & Reference \\
\hline Cosmetics & $\begin{array}{l}\text { Skin, hair, and oral care products; } \\
\text { Lipsticks; Deodorants }\end{array}$ & [87] \\
\hline Pharmaceutical & $\begin{array}{l}\text { Controlled drug release; pills coating } \\
\text { and stabilizer; antibacterial, antitu- } \\
\text { mor, antioxidant and anticoagulant } \\
\text { agent; nutritional aid for weight loss }\end{array}$ & $\begin{array}{c}{[71,89,90,} \\
143--146]\end{array}$ \\
\hline Biomedical & $\begin{array}{l}\text { Wound dressing; thromboresistant } \\
\text { and antimicrobial coatings; scaffolds } \\
\text { for tissue engineering; cell delivery } \\
\text { systems; gene delivery }\end{array}$ & $\begin{array}{c}{[144,147--} \\
150]\end{array}$ \\
\hline Agriculture & $\begin{array}{l}\text { Microbial infection preven- } \\
\text { tion;biofungicide }\end{array}$ & {$[100,144]$} \\
\hline $\begin{array}{l}\text { Food indus- } \\
\text { tries }\end{array}$ & $\begin{array}{l}\text { Food shelf life improver; preserva- } \\
\text { tive; thickener; moisture loss preven- } \\
\text { tion }\end{array}$ & {$[101,144]$} \\
\hline $\begin{array}{l}\text { Textile indus- } \\
\text { tries }\end{array}$ & $\begin{array}{l}\text { Antimicrobial coatings; moisture } \\
\text { control; dye absorption }\end{array}$ & $\begin{array}{c}{[64,88,} \\
144]\end{array}$ \\
\hline $\begin{array}{l}\text { Wastewater } \\
\text { treatment }\end{array}$ & $\begin{array}{l}\text { Coagulation and flocculation agent; } \\
\text { removal of heavy metal ions }\end{array}$ & {$[91,144]$} \\
\hline
\end{tabular}

Biocompatible and biodegradable chitosan-based microspheres and hydrogels can be employed for the delivery of a wide variety of drugs in a controlled/sustained manner. As comprehensively reviewed by Mitra and Dey [152], chitosan microspheres can be prepared by different techniques such as self-assembly of positively charged chitosan with polyanions (i.e. ionotropic gelation), emulsion cross-linking, thermal cross-linking, coacervation/precipitation, spray drying and sieving, among others. Hydrogels are three-dimensional (3D) hydrophilic polymeric networks in which the solid phase typically represents less than $10 \%$ of the total volume of the gel and that can thus absorb huge volumes of water, as recently reviewed by Ahmadi and colleagues [153]. Chitosan-based hydrogels can be prepared by physical crosslinking, exploiting ionic interactions (e.g., ionically cross-linked and polyelectrolyte complexed chitosan hydrogels), secondary interactions (e.g., entangled chitosan-based hydrogels [154]), or by chemical cross-linking, allowing to obtain a wide variety of assemblies with specific mechanical, thermal and biological properties that can be tuned by changing the composition of the gel. Specific medical applications of chitosan microspheres and hydrogels involve gastrointestinal, colon, ophthalmic, oral, nasal, transdermal and vaginal drug delivery $[152,155]$.

Interestingly, injectable thermosensitive hydrogels combining chitosan with glycerophosphates or other weak bases have been developed [156]. They do behave liquid-like at temperatures between 4 and $20^{\circ} \mathrm{C}$ but, upon injection into the body at $37^{\circ} \mathrm{C}$ they form semi-solid gels allowing local controlled drug delivery [157].

In addition, chitosan and their derivatives can be formulated in micelles for the delivery of poorly soluble pharmaceuticals, mainly anticancer drugs such as paclitaxel, Mytomycin C, doxorubicine, and camptothecin $[158,159]$.

Chitosan has also been thoroughly investigated as highly cytocompatible non-viral gene delivery vector in gene therapy approaches $[150,160]$. Chitosan is positively charged in solution at 
slightly acid $\mathrm{pH}$, thus interacts electrostatically with nucleic acids and self-assemble with them to form nano/micrometric complexes named polyplexes that are capable to enter eukaryotic cells and deliver their content. The gene delivery activity of native chitosan has been demonstrated both in vitro and in vivo $[161,162]$ but its efficiency is lower as compared to other polymeric non-viral vectors. Several chitosan derivatives have thus been synthesized by grafting to the chitosan chain other cationic polymers more effective for this purpose, such as low Mw polyethylenimine (PEI) [163] and hydrophilic, hydrophobic, $\mathrm{pH}$-sensitive, thermosensitive and cell-specific moieties [164].

\subsubsection{Biomedical Applications}

The versatility and the many favorable biological properties of chitosan and its derivatives greatly widen the number of their biomedical applications they are used in, spanning from wound healing to tissue engineering, from gene delivery to antibacterial coatings.

Owing to their high water content, biodegradability, biocompatibility, porosity, tunable properties, and ability to promote cell adhesion and proliferation, chitosan-based hydrogels have been widely employed as scaffolds for tissue engineering purposes and as (thermosensitive) injectable cell delivery systems for tissue regeneration [69]. Specifically, they are investigated for engineering/regenerating various tissues such as bone, cartilage [165], skin [166], blood vessels [167], and nerves [168].

All the aforementioned properties make chitosan also very suitable for wound dressing/healing. Several commercial wound care products working as effective antibacterial barriers are already on the worldwide market, even if not all are EMA and FDA approved (e.g. HemCon ${ }^{\circledR}$, ChitoFleX $^{\circledR}$, ChitoGauze $^{\circledR}$, Chitodine $^{\circledR}$, Tromboguard $^{\circledR}$, Tegaderm ${ }^{\mathrm{TM}}$ ). Chitosan, processed in different forms such as sponges, films, and nanofibrous porous and non-woven membranes, in fact, can provide a hydrated 3D matrix for tissue growth that allows for high gas exchange, and protect from microbial infections [169]. Furthermore, chitosan has been demonstrated to promote the activity of macrophages, leukocytes, and fibroblasts, thus stimulating and enhancing extracellular matrix (ECM) deposition along with possibly preventing excessive scar formation [170].

\section{MAIN TECHNIQUES TO OBTAIN ANTIBACTERIAL CHITOSAN COATINGS: ADVANTAGES, LIMITATIONS, AND APPLICATIONS}

As previously mentioned, pathogenic microorganisms can adhere to the surfaces of medical devices, causing serious infections and clinical complications (Section 2). Antibacterial chitosan coatings can meet the current urgent need of biomaterials with inherent antibacterial properties, to which microorganisms cannot develop resistance as it often happens with antibiotics. Furthermore, as described in section 4 , chitosan coatings are promising due to their biocompatibility, antimicrobial activity at low concentrations and their broad antimicrobial spectrum. This section is thus dedicated to the description and evaluation of the main methodologies employed to produce antibacterial chitosan coatings, their advantages, their limitations and their main applications in the biomedical field.

Several techniques can be used in order to produce chitosan coatings with antibacterial properties. However, to immobilize these coatings on biodevice surfaces, two main approaches are commonly used: physical deposition based on surface secondary interactions such as electrostatic and Van der Walls forces and hydrogen bonding, or surface grafting leading to stable covalent attachment $[171,172]$. The approach of choice will depend on the specific application: for example, if the coating should be stable at long-term, as expected for devices such as vascular catheters, orthopedic prosthesis, dental implants and other implantable devices, the covalent attachment will be preferred. However, if biodegradation is expected such as in drug delivery systems and tissue engineering scaffolds, or if the antibacterial activity is needed only at short term as for wound dressing applications, adsorption/deposition approach based on physical interactions will be preferred [70, $171,173]$.

Independently of the target application, the production of chitosan coatings basically consist of two steps: material surface preparation/activation and immobilization of the chitosan coating.

\subsection{Material Surface Preparation/Activation}

Before the deposition of any type of coating, the material surface must first be cleaned, usually by several washing steps in a solvent or/and aqueous solution, followed by physical or chemical activation to improve the coating adhesion. Cleaning steps are required in order to ensure that grafting or coating is done on materials and not on contaminants which would lead to premature detachment. Pre-treatments of biomedical device surfaces for subsequent coating with chitosan (by physical, chemical or physical/chemical techniques) are briefly detailed thereafter, and summarized in Table 7 .

\subsubsection{Physical Pre-treatments}

Physical surface pre-treatment techniques are commonly employed for metallic substrates.

\section{Mechanical Polishing}

Mechanical polishing is performed by using abrasive papers [15], (sand, silicon carbide, diamond papers), using different grits to obtain the desired finishing or roughness.

\section{Blasting}

Blasting process is performed in order to increase the surface roughness to increase the adhesion strength of the coating. It is done by driving, under high pressure, a stream of abrasive particles (sand, alumina, glass etc.) onto the surface [174].

\subsubsection{Physical/chemical Pre-treatments}

Among physical/chemical pre-treatments, anodization is also performed only on metallic substrates, whereas plasma techniques are usually performed for surface modification of polymers such as PEEK, PU, PTFE, PP, etc.

\section{Anodization}

In the anodization process, the substrate to be modified is used as the anode in an ionic solution, an oxidation reaction occurs at the surface increasing the thickness of the natural oxide layer. The oxide layer is often porous allowing the reaction with the underlying metal and the incorporation of bioactive agents [187] and to improve the adhesion of the successive chitosan coatings [178].

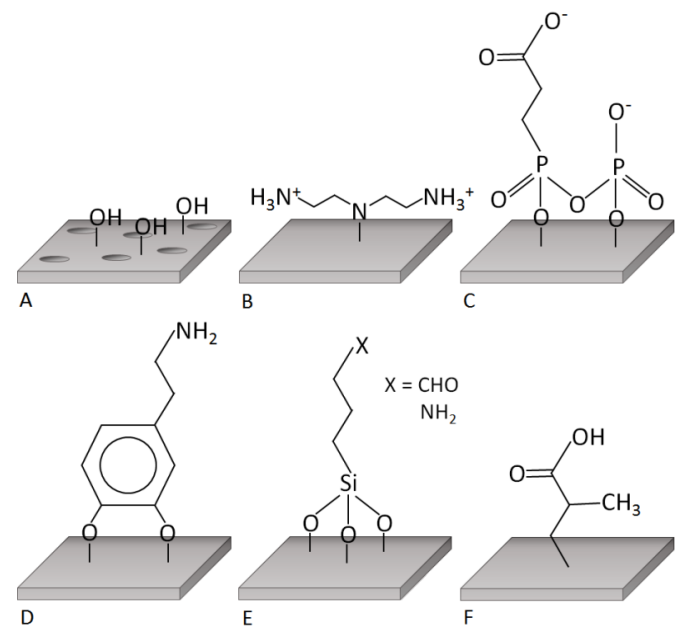

Fig. (10). Schematic representation of surface activation by (A) harsh acid solution (e.g., piranha), (B) halamine, (C) phosphates or phosphonates derivatives, (D) dopamine, (E) silanol, and (F) methacryl acid. 
Table 7. Surface treatments employed before the deposition of chitosan-based coatings. Graft. and Ads. indicate, respectively, grafted and adsorbed coatings.

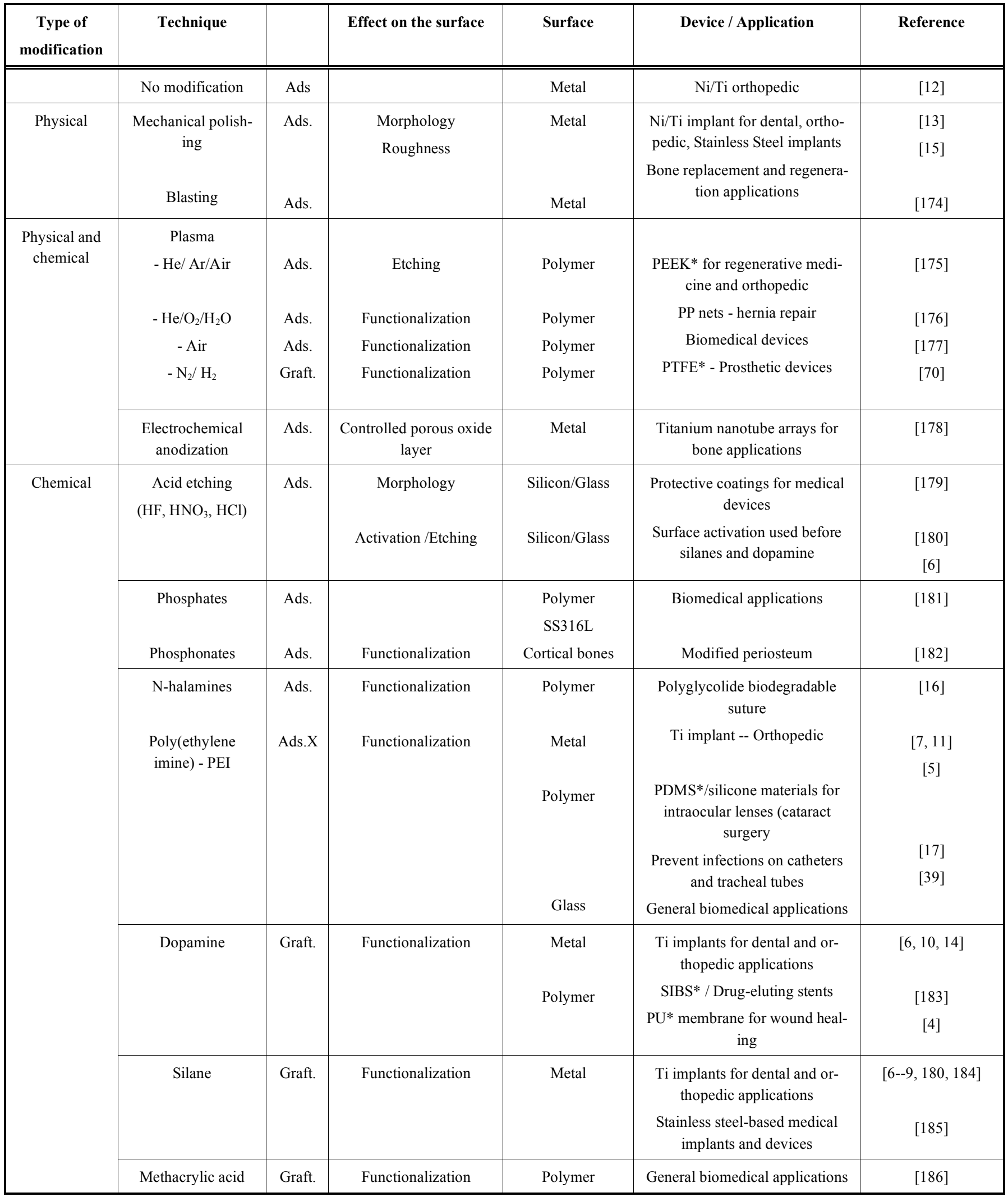

* PEEK poly(ethylene ether ketone), polyurethane (PU), poly(tetrafluoroethylene) (PTFE), polypropylene (PP), poly(styrene-b-isobutylene-b-styrene) (SIBS), polyvinylfluoride (PVF) 


\section{Plasma Technique}

In a general way, plasma can be defined as the fourth fundamental state of matter, where a totally or partially ionized gas is obtained by electrical discharges originating radicals, electrons, ions, neutral atoms and/or metastable and unstable molecules. Plasma allows to modify only the first layer of materials without changing its bulk properties, is eco-friendly (no solvent) and versatile, furthermore it is already an industrial technique [188, 189]. By varying parameters such as power, pressure, treatment time, but also the feed gas, the effect of plasma on the substrate can be easily changed and adapted depending on the desired surface modification [189-193]. As pre-treatment for chitosan coatings, two main types of effects can be obtained:

-Surface etching by using argon or helium leads to an increase in the coating adhesion [175],

-Surface functionalization with water vapor, air, carbon dioxide, nitrogen/hydrogen, etc., permits to introduce hydrophilic groups on the surface, allowing an increase in the chitosan coating/surface adhesion through Van der Walls or hydrogen interactions [176, 177, 194]. When used for the grafting approach, these functional groups act as anchor points for chitosan grafting, leading to the formation of covalent stable bonds [70].

\subsubsection{Chemical Modifications}

In wet chemistry, chemical solutions are used to introduce functional groups or charges, or to change the surface hydrophilicity, morphology and roughness (e.g., etching by acid-basic solutions) of the substrate biomaterials aiming to increase the chitosan coating adhesion [171]. This approach offers many different strategies to functionalize material surfaces, thus they can be considered as a versatile platform.

In some case, pre-treatments with harsh acidic solution such as piranha one $\left(\mathrm{H}_{2} \mathrm{SO}_{4} / \mathrm{H}_{2} \mathrm{O}_{2} / \mathrm{H}_{2} \mathrm{O}\right)$ or Kroll's reagent $\left(\mathrm{HF} / \mathrm{HNO}_{3} / \mathrm{H}_{2} \mathrm{O}\right)$ are done in order to increase the density of hydroxyl groups (Fig. 10A), on the metallic or glass surface $[6,171,180]$ before further functionalization with dopamine, silanol, phosphates, etc. Although, these pre-treatments are very efficient for the removal of organic impurities [179].

Regarding surface functionalization, it can be done by using various reagents, , as shown in Table 7, leading to different chemical functionalized surfaces (Fig. 10), which are then used as anchor points for ionic interactions for adsorption techniques or for chemical grafting of chitosan or its derivatives.

In order to have ionic interactions, the surface of the device can be functionalized with chemical functionalities leading to a highlycharged surface: to obtain a positive charge, ammonium derivatives (Fig. 10B) $[5,7,11,16,17,39]$ are commonly used whereas for a negative charge (Fig. 10C), anionic reagents, such as phosphates [181], carboxylic acids [182] have been investigated. To maximize the interactions with the antibacterial chitosan-based coatings, polycations and polyanions can also be used:

- Polycationic agents such as halamines (Figure 10B) [16], poly(ethyleneimine) (PEI) $[5,7,11,17,39]$ can be adsorbed on the surface after its activation;

- The most employed polyanions are polyphosphates (Figure 10C) such as sodium tripolyphosphate (TPP), sodium pyrophosphate (PP), and sodium hexametaphosphate (HMP) that are anchored on pre-activated surfaces [181]. The phosphonate approach can also lead to free carboxylic end groups by using 11-phosphonoundecanoic acid (PUA), for example [182].

The grafting approaches for chitosan-based coatings aim at creating stable covalent linkages between the surface and the antibacterial coating. The most commonly used approaches are:

- Dopamine: the reactivity of dopamine is based on its catechol moieties known to form stable bonds with surfaces (Fig. 10D).
Furthermore, its capability to polymerize on various substrates, from metals, to organic polymers and to inorganic materials [10, $61,90,195-197]$ makes dopamine functionalization a very attractive strategy in stable coating deposition. Indeed, biomedical devices can be easily fully and uniformly covered by a dopamine layer, which can thereafter react with amine groups present on chitosan by Michael addition or Schiff base reaction to produce covalently attached antibacterial coatings [4, 6, 10, 14, 90, 183].

- Silanization is another very attractive surface activation technique, for metallic surfaces, due to the versatility of the various silanol derivatives available. Indeed, silanol moieties react with the hydroxylated substrate leading to a stable covalent link (Fig. 10E), whereas the terminal end groups remain available for the chemical grafting of the chitosan-based-coating. For example, (aminopropyl) triethoxysilane (APTES) $[6-8,180]$ leads to terminal amines whereas triethoxsilylbutyraldehyde (TESBA) $[8,9,184]$ to aldehydes.

- Polymeric surfaces can be functionalized by using methacrylic acid, for example, as shown by Lv et al. [186] (Fig. 10F), leading to free carboxylic acids used to anchor the chitosan-based antibacterial coating.

\subsection{Chitosan Coating Deposition/grafting Techniques 5.2.1. Deposition Techniques by Physisorption} 5.2.1.1. Simple Adsorption

The simplest way to produce chitosan coating is to cast a chitosan solution over the substrate, or immerse the substrate in the solution and let the solvent evaporate. This process occurs at the liquidsolid interface and it is based on the interface charges [198]. The main advantages of this technique are its simplicity and facility to perform at low cost. Another important issue is this it is a reversible process, without chemical changes [198] between the substrate and chitosan coating, in this regard, the antibacterial activity of the coating can be increased due to higher the availability of free amines (no chemical bond with the surface). However, the quality of chitosan coatings produced by simple adsorption is limited, control over the coating properties is difficult and delamination can easily occur.

An example of application of chitosan coating obtained by simple adsorption is reported by Sulek and colleagues that developed chitosan-based antimicrobial coatings for orthopedic implants, previously mechanically ground and etched by sulfochromic acid. Tests with $S$. epidermidis and $S$. aureus showed that the number of bacteria attached to the surface coated with chitosan was lower if compared to bare surfaces [199]. Moreover, cotton gauzes were functionalized by carboxymethyl chitosan-calcium alginate solution coating to produce a wound healing dressing featuring moisture holding and antibacterial activity that was demonstrated on E. coli and $S$. aureus [200]. In another recent work, Vicryl, a commercial absorbable suture was directly coated with hydroxypropyl trimethyl ammonium chloride chitosan dissolved in type I collagen solution and it was compared with Vicryl Plus, a similar suture with antibacterial properties. Methicillin-resistant $S$. epidermidis and $S$. aureus were employed to perform the antibacterial tests evaluating the bacterial adhesion and biofilm formation on the sutures and human skin-derived fibroblasts cells were used to test the cytocompatibility. Results showed that hydroxypropyl trimethyl ammonium chloride chitosan-coated Vicryl sutures exhibited antibacterial activity comparable to that of Vicryl Plus sutures together with good cytocompatibility [201].

\subsubsection{Dip Coating}

The dip coating is a simple and low-cost technique to cover surfaces with a thin film usually of high quality. Similarly, to simple adsorption method, the chitosan coatings obtained by dip coating can present a high number of free amine groups but, unfortunately, delamination process can occur at long term. In a general way, this technique consists of three steps [202,203]: 
- Immersion and dwell time: the substrate is dipped into the solution and the dwell time should be sufficient to let occur interactions between the surface and the solution;

- Deposition and drainage: the substrate is pull up with a constant speed and the excess solution is drained from the surface;

- Evaporation: the solvent evaporates forming a thin film on the surface.

For example, chitosan/poly(vinyl pyrrolidone) (CHI-PVP) coatings obtained by dip coating on preactivated PET devices demonstrated a decrease in the adherence of $S$. aureus and $E$. coli together with bactericidal activity. Furthermore, no cytotoxicity was observed in human umbilical vein endothelial cells (HUVEC) seeded on the modified surfaces [204]. Chitosan nanoparticlespolymethylacrylate and chitosan colloids-polymethylacrylate, were also dip coated on glass substrates. These surfaces exhibited antibacterial behavior against $S$. aureus, with superior activity demonstrated for chitosan colloids-polymethylacrylate coatings [205].

In another work, Ignatova et al. produced electrospun fibers dip-coated with quaternized chitosan and k-carrageenan, leading to significant antibacterial activity against $S$. aureus and $E$. coli but also with antioxidant activity due to the combined presence of quaternized chitosan and k-carrageenan. These fibers with dual effect are promising for wound healing dressings [206].

\subsubsection{Laver-by-layer (LbL)}

Chitosan coatings can also be produced by layer-by-layer ( $\mathrm{LbL})$ deposition. In this technique, the substrate is previously electrically charged through a functionalization technique (e.g., plasma, piranha solution, etc.) and is then, sequentially dipped in polyelectrolyte solutions with opposite charges, thus depositing successive layers of opposite charge. Importantly, each deposited layer must have a minimum charge density to attract the other polyelectrolytes with opposite charge. The repetition of the adsorption sequence forms the final multi-layered coating [207--209]. LbL technique allows the utilization of different polyelectrolytes such as synthetic polymers (e.g., polyacrylic acid (PAA), polyethylenimine (PEI), etc.) or natural polymers (e.g., chitosan, alginate, hyaluronic acid, etc.) to cover different types of substrates with irregular shapes and sizes, in an easy and versatile coating production process. Some examples of the use of LbL technique to obtain antibacterial chitosan coatings are briefly described below.

Heparin/chitosan LbL coatings were deposited on aminolyzed PET substrates. The antibacterial and antiadhesive properties of the coatings were evaluated using $E$. coli and it was shown that a superior bacterial reduction could be obtained for layers prepared at low $\mathrm{pH}$ (i.e., $\mathrm{pH} 3.8$ ) with respect to slightly acidic $\mathrm{pH}$ (i.e., $\mathrm{pH}$ 6.0), owing to the higher amount of electronically charged chitosan chains present on the surface of the coating [62].

Richert and colleagues [210] thoroughly investigated the process of deposition of chitosan/hyaluronic acid films by LbL demonstrating that low MW chitosan and high ionic strength (i.e., 150 $\mathrm{mM} \mathrm{NaCl}$ ) allow a faster film growth. Interestingly the films obtained at high ionic strength demonstrated a significant resistance to bacterial adhesion $(80 \%$ reduction using $E$. coli) but also eucaryotic cell adhesion was impaired [210]. The antibacterial properties of chitosan/hyaluronic acid LbL films were confirmed by another study where silicon $(\mathrm{Si})$ wafers pre-treated with PEI were employed and a reduction of up to $99 \%$ of bacterial colonies (S. epidermidis) adhered to the functionalized substrates was observed [211]. Recently, aiming to optimize the LbL deposition of chitosan/hyaluronic acid nanofilms and to maximize their antibacterial activity, Hernandez-Montelongo and collaborators [39] investigated the relation between the $\mathrm{pH}$ of the polysaccharides solutions and both the growth of the nanofilms and their antibacterial effect. In this study, a single PEI pre-layer was deposited onto the bare surfaces, and the results showed that deposition at $\mathrm{pH} 3$ led to the maximal exposure of chitosan chains (and their free ammonium groups) on top layer of the surface and consequently to improved antibacterial activity, with a reduced cell density of 5 orders of magnitude against $S$. aureus (Gram-positive). Furthermore, it was shown that surface charge density and antibacterial activity increased by increasing the number of bilayers. However, unexpectedly, only a limited antibacterial effect was observed for $P$. aeruginosa (Gram-negative), these results suggest a bacterium-specific activity of these chitosan coatings and a lower efficiency against Gram-negative bacteria, possibly owing to their outer cell membrane [39]. Chitosan/hyaluronic acid LbL coatings were also employed to coat intraocular lens, pre-coated with a single PEI layer. The results showed that chitosan could provide antimicrobial activity against $E$. coli and $S$. aureus by two ways, reducing the bacterial adhesion and killing the bacteria attached to the substrate. On these premises, the authors propose this coating for the prevention of post-cataract surgery infectious endophthalmitis [5].

A particular strategy to produce all-chitosan-based LbL films was proposed by Bulwan et al. that employed cationic and anionic chitosan derivatives (a cationic polyelectrolyte based on chitosan substituted with quaternary amines and an anionic polyelectrolyte based on chitosan substituted with sulfonate groups) for the deposition on $\mathrm{Si}$ and glass surfaces pre-treated with piranha solution. Noteworthy, the developed surfaces demonstrated antifouling, antibacterial and anticoagulant properties making them promising versatile protective coatings for medical devices and tools that come into contact with blood [179].

To prevent bone allografts suffer failure due to poor integration and infection, chitosan-heparin coatings were deposited via LbL on pre-activated cortical bones. Results showed that the deposition of a PUA pre-layer enabled the formation of chitosan-heparin layers resulting in the complete coverage of the surface and significant antibacterial activity against $S$. aureus and E. coli. Surprisingly, notwithstanding the presence of the coating bone cells could probably still interact with adhesion ligands presents on the surface of the bone and the adhesion of mesenchymal stem cells was not inhibited [182].

\subsubsection{Spray Coating}

Spray coating is a deposition technique that employs gas flow to separate a fluid into small droplets and direct them onto the surface of a substrate where a film is deposited. This technique allows obtaining homogeneous coatings in short deposition times on substrates with various geometries [212--214]. Furthermore, electrostatic forces can be exploited to improve the adherence of the coating and to produce stable polyelectrolyte multilayers. However, the deposition parameters, such as, distance from the sample, nozzle, needle opening (fluid flow), pressure and spraying time play a determinant role in obtaining a quality coating.

Mitra and collaborators coated polymeric and metallic substrates with quaternized chitosan. For the two treated substrates, it was observed antibacterial activity against $S$. aureus and $P$. aeruginosa and no cytotoxicity on 3T3 mouse fibroblast cells. Besides, the coatings were highly stable to wiping [181]. In another study, glass substrates were coated with polyelectrolyte multilayers of chitosan and hyaluronic acid functionalized with cateslytin (an antimicrobial peptide). Interestingly, antimicrobial activity increased with the number of deposited bilayers, up to the complete inhibition of the development of $S$. aureus and of the fungus Candida albicans, combined with a limited fibroblasts adhesion on these coatings which have been thus proposed for applications such as catheters or tracheal tubes where tissue growth is not desired and infections should be prevented with extreme care [17].

\subsubsection{Spin Coating}

The spin-coating technique involves the application of a solution containing the compound to be deposited (usually polymers) on a flat substrate, followed by rotation at high speed, causing the liquid to undergo centrifugal acceleration so that it spreads throughout 
the substrate. When the excess liquid is ejected from the substrate, the solvent evaporates leaving a uniform thin film. The thickness of the coating is a function of rotation speed, viscosity of the solution, concentration of the deposited agent and of the type of solvent. Despite this technique is widely employed, among the main disadvantages there are material wasting and the limited type of geometries that can be processed [215].

A representative application of this technique is reported by Sutha and co-workers. They coated stainless steel implants for orthopedic applications with a chitosan solution blended with Sidoped hydroxyapatite powders. Remarkably, the antibacterial activity against $E$. coli and $S$. aureus increased with the amount of substituted $\mathrm{Si}$ in hydroxyapatite, possibly owing to a different amount and distribution of the negative surface charges of the Si-doped hydroxyapatite component [216]. In another work, in order to develop titanium implants with anticancer and antibacterial properties, $\mathrm{TiO}_{2}$ nanotubes were produced to work as selenium nano-reservoirs and coated by a chitosan layer. Results demonstrated that this material could inhibit the proliferation of cancerous osteoblasts while promoting that of healthy osteoblasts and at the same time it exhibited antibacterial properties when tested against E. coli [178].

\subsubsection{Electrospraving}

Electrospraying is a technique that exploits electrical forces to atomize fluids. The fluid, flowing through a capillary nozzle maintained at high potential, is forced by the electric field to be dispersed into droplets that are directed towards a grounded and heated substrate where the macromolecules they carry are deposited upon evaporation of the solvent. The size of the droplets can be finely tuned by changing the process parameters with radii from few nanometers to hundreds of micrometers, thus allowing to obtain coatings with different topographies [217]. The use of electrospraying has been often proposed in combination with chitosan to obtain antibacterial coatings for biomedical devices, especially in the orthopedic and dental fields.

To improve the properties of NiTi alloys for orthopedic applications, chitosan blended with gold nanoparticles was electrodeposited on these surfaces. Results showed that the coating reduced the Ni release, improved the corrosion resistance and possessed fast and long-lasting antibacterial effectiveness against $S$. aureus [12]. Similarly, also, chitosan/Ag composite coatings were deposited by electrospray on NiTi alloys, showing once again good antibacterial activity [13].

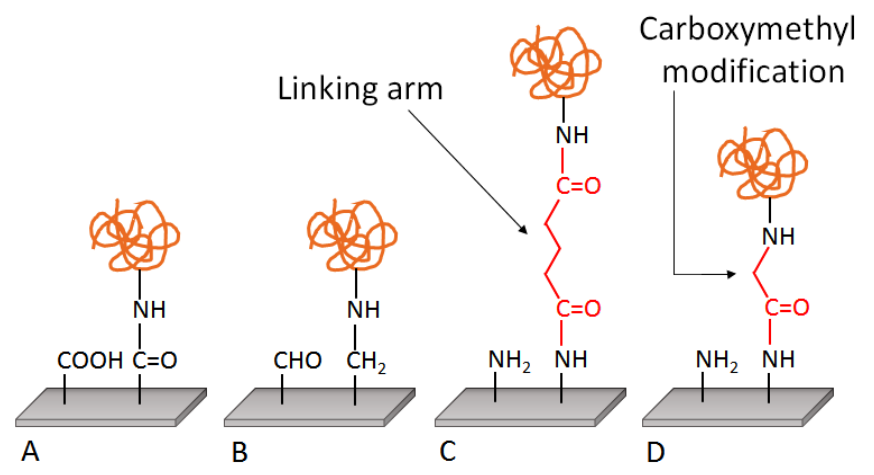

Fig. (11). Schematic representation of the approaches employed for the grafting of chitosan on biomaterial surfaces. Chitosan is directly linked to the (A) $\mathrm{COOH}$ or (B) $\mathrm{CHO}$ groups present on the surface; chitosan is grafted to the $\mathrm{NH}_{2}$ groups present on the surface by (C) a bifunctional linker or (D) directly by exploiting chemical functionalities introduced in the chitosan structure, in the example carboxymethyl chitosan is reported.

\subsubsection{Electrophoretic Deposition}

In the electrophoretic deposition, the charged colloidal particles, in suspension, migrate under the action of an electric field and are deposited on an electrode. In the case of chitosan coatings, the substrate material is cathodically polarized and the deposition is due to the local $\mathrm{pH}$ variation caused by electrochemical decomposition of water; in fact, a high $\mathrm{pH}$ region is produced at the cathode where the loss of charge of the chitosan amine groups lead to the formation of an insoluble deposit [218]. This technique is not expensive and versatile, enabling to produce homogeneous coatings on complex geometries, without using expensive apparatuses. However, the production of high quality chitosan coatings with the desired thickness and homogeneity properties by this technique can be complicated if variables as $\mathrm{pH}$ and temperature are not finely controlled. In particular, $\mathrm{H}_{2}$ bubbles are formed at the cathode and their presence can affect the smoothness of the surface. In addition, electrodeposited chitosan coatings are not stable in acidic conditions [219]. Examples of proposed applications of electrodeposited chitosan come once again from the orthopedic field. Recently, titanium surfaces were coated with chitosan-vancomycin by cathodic electrophoretic deposition. The coating reduced the number of $S$. aureus colonies due to chitosan action, further improved by the antibiotic vancomycin, and did not show any adverse effect on biocompatibility when it was tested with osteoblast-like cells [220]. In another similar study, electrophoretic deposition was used to produce coatings composed of bioactive glass particles and chitosan on stainless steel and TiA14V6 alloys. An important antibacterial effect against $E$. coli was observed for all the developed coatings. The coating was homogeneous and displayed high adhesion to the substrate by tape test on planar samples, but it was not possible to produce homogeneous coatings on complex geometries (metal foams made from TiAl4V6 alloy) [221].

\subsection{Grafting of Chitosan Coatings on Biomaterial Surfaces}

Grafting of chitosan on the surface allows the strong attachment of the coating by covalent bonds and can be accomplished by different approaches, as summarized in the Fig. 11:

- The coating is linked directly to the surface (Fig. $11 \mathrm{~A}, \mathbf{B})$ due to chemical functionalities present in the material structure or introduced by previous chemical modification of the surface (as described above in 5.1.3);

- The grafting occurs through a linking arm (e.g., glutaric anhydride, glutaraldehyde, bifunctional poly(ethylene glycol), etc.), used to indirectly link the coating to the pre-functionalized substrate (Fig. 11C) [70, 171, 172, 222];

- The grafting occurs by using chitosan modification (Fig. 11D), leading to reactive groups able to react with the functionalized surface [223].

\subsubsection{Directly Tethering Chitosan Coatings on Biomaterial Sur-} faces

The directly covalent immobilization of chitosan coatings onto the substrate can be performed by several ways. Among them, the most employed is the surface functionalization by aldehydes and carboxylic groups. These functionalities are able to react with nucleophilic groups from chitosan, such as amines and alcohols, leading to a covalent bond, originating a stable chitosan coating. However, due to the higher reactivity of amines, the reaction with amine moieties occurs preferentially thus leading to loss of free amines for antibacterial activity.

\section{Chitosan Grafting on Surfaces Pre-activated with Carboxylic Groups}

As described in section 5.1.3., carboxylic groups can introduced on the surface, for example, by acrylic acid (AA) grafting. Using this approach, Lv and collaborators [186, 194] grafted chitosan 
coatings onto PU surfaces by methacrylic acid linkages, which presented a good biocompatibility when tested with mammalian cells and a long action against $S$. epidermidis, $S$. aureus, and E. coli. Furthermore, it was possible to incorporate in the coatings anionic antibiotics (e.g., rifampin), extending their release time and thus improving the long-term antibacterial behaviour [186]. Chitosan was also grafted on acid-activated nonwoven PP, useful for the production of pads and fabrics used in hospitals, demonstrating antibacterial activity towards $P$. aeruginosa [224]. In another work, the grafting of chitosan-Rose Bengal (CHRB) trough chitosan amine groups and carboxylic acid of PDMS activated substrates was performed in order to reduce the risks of bacterial infection during surgical application. The CHRB coating antibacterial activity was investigated using $E$. coli and $S$. aureus and results suggested a preferential bactericidal activity against Gram-positive bacteria [225].

\section{Chitosan Grafting on Surfaces Pre-activated with Aldehyde Groups}

Aldehyde-functionalized surfaces can be obtained by using, for example, triethoxysylilbutyraldehyde (TESBA) as described in section 5.1.3. These terminal aldehydes are very reactive towards amines and alcohols. For instance, titanium dental implants previously activated by aldehydes led to a stable chitosan coating due to covalent grafting, exhibiting great scratch resistance, and also a significantly higher adherence than a simple chitosan deposition, as evidenced by indentation and scratch tests. Furthermore, the chitosan grafted titanium implants exhibited good biocompatibility to NIH3T3 fibroblasts, strong inhibition of Actinomyces naeslundii growth; nonetheless they showed a non-significant inhibition against Porphyromonas gingivalis, which can be explained by the lower antibacterial activity of chitosan against Gram-negative bacteria [184].

\subsubsection{Tethering Chitosan Coatings on Biomaterial Surfaces Us- ing a Linking Arm or Chitosan Modification}

The covalent immobilization of chitosan coatings employing a linking arm occurs when the preactivated surfaces exhibit terminal amine groups, as described in subsection 5.1 for dopamine, aminosilane (APTES) and $\mathrm{N}_{2} / \mathrm{H}_{2}$ plasma treatments. Indeed, amine groups present on the substrate cannot react directly with amine moieties of chitosan, therefore it is necessary to use a homo or hetero-bifunctional linking arm, that possesses terminal carboxyl or derivatives (e.g., N-hydroxysuccinimide, NHS), or aldehyde reactive groups (e.g., glutaraldehyde) [8]. This approach permits to obtain covalently bonded stable chitosan coatings, but it adds a step in the surface processing and makes the procedure longer. However, the reactions with linking arms are often easily performed in buffer solutions. Furthermore, the use of specific spacer-containing linking arms, such as PEG spacers of different length, could be helpful regarding antibacterial coatings, as PEG is known to be anti-fouling thus possibly permitting to combine bacteria-repelling behaviour with the bactericidal properties of chitosan [70].

Another way to graft chitosan directly on previously aminated surfaces is to modify chitosan reactive groups $\left(\mathrm{NH}_{2}, \mathrm{CH}_{2} \mathrm{OH}\right)$ with other functionalities, such as carboxymethyl moieties [6], able to directly react with the amino functionalized surface. This approach induces chemical modification of chitosan, which should be well controlled, and also introduces the need of further purification steps. However, as described in section 4.5 (Tab. 5), this chitosan modification can be also an added value as it can improve biological properties: for example, carboxymethyl chitosan has been shown to induce hemocompatibility properties, but also to have a high antibacterial activity.

Chitosan Grafting on Pre-activated Surfaces by Using a Linking Arm

In a preliminary study, Vaz and coworkers [70] evaluated the influence of three linking arms, exploiting the reaction between carboxylic and amine groups, on the grafting of chitosan on plasmaaminated PTFE substrates, aiming to identify structure-property relationships. The short glutaric anhydride linker (Mw: $114 \mathrm{Da}$ ), was used due to its low steric mobility and led to chitosan coatings with high proximity to the substrate. Poly(ethylene-alt-maleic anhydride) was used as long, high Mw linker (Mw: 100-500 kDa). This anchor molecule allowed multiple linking points with both the substrate and the chitosan molecules. Finally, a PEG-based bifunctional linker, poly(ethylene glycol) bis(carboxymethyl) ether (Mw: $600 \mathrm{Da}$ ), with carboxymethyl groups at both the extremities, was used aiming to combine the PEG antiadhesive properties with the bactericidal ones of chitosan. Chitosan coatings showed good stability and the type of anchor used influenced the quality of the obtained coatings, with the glutaric anhydride-based coatings being the most homogeneous. Unfortunately, no antibacterial tests were performed, thus hindering to draw structure-activity relationships [70]. In another study, chitosan-lysozyme coatings were grafted on stainless steel surfaces activated by dopamine with glutaraldehyde as a homo-bifunctional linker. Bioconjugation of chitosan with the antibacterial enzyme lysozyme was aimed at improving the antibacterial efficiency of the coating, especially under non-acidic conditions. Results showed that lysozyme moieties could further enhance the antibacterial activity of chitosan coatings against $S$. aureus under neutral $\mathrm{pH}$ conditions [61].

Modified hydrophobic chitosan coatings on magnetic nanoparticles have been recently proposed for an interesting biomedical application: the removal of bacteria and biofilms from contaminated surfaces [226]. Chitosan was modified by grafting with dodecyl hydrophobic tails and then deposited on the surface of magnetic nanoparticles activated by aminosilane through glutaraldehyde grafting. The developed hydrophobically modified nanoparticles were able to capture and coagulate Gram-negative bacteria (E. coli, capturing capacity: $1.38 \times 10^{8}$ cells $/ \mathrm{mg}$ ), that could not be captured at all by nanoparticles coated with plain chitosan.

\section{Chitosan Grafting on Aminated Surfaces by Chitosan Modifica- tion}

Carboxymethyl chitosan is often used as chitosan derivative to coat aminated surfaces, due to its chemical reactivity and to the preserved antibacterial activity. As a practical example, medical silicone surfaces were pre-treated with dopamine and then modified with carboxymethyl chitosan. Antibacterial assays showed that the coating could significantly reduce the adhesion of E. coli and Proteus mirabilis, even if without an outstanding efficiency (i.e., ca. $90 \%$ ), and cytotoxicity was not observed when treated surfaces were tested with fibroblasts [223].

In a comparative study, it was evaluated the stability of carboxymethyl chitosan coatings grafted onto Ti surfaces using dopamine and aminosilane as surface pre-functionalization agents. The carboxymethyl chitosan coatings efficacy against $S$. epidermis was demonstrated, however, surprisingly, chitosan coatings anchored with aminosilane presented a decreasing stability after contact with $70 \%$ ethanol treatment, autoclaving, and immersion in PBS [6]. These results demonstrated the need of performing systematic characterizations of the coatings not only in terms of antibacterial activity but also of stability in different milieus, upon sterilization and cleaning techniques, aspects that are often underestimated and overlooked in the development of chitosan-based antibacterial coatings.

\section{CONCLUSION}

The development of antibacterial coatings for biomedical devices has been strongly prompted in the last 20 years owing to the increasing awareness and understanding of the healthcareassociated infections and particularly of biomaterial-associated infections together with the parallel growth of antimicrobial resistant pathogens that limit the usefulness of the traditional antibioticbased approaches. 
A wide variety of approaches have been investigated, relying mainly on coatings for antibacterial agent release, contact killing and adhesion resistant surfaces. Even if the release of antibacterial agents can take advantage of compounds with recognised strong activity such as antibiotics, the release kinetics must be finely tuned to obtain the desired effects, pathogens can develop or have already developed resistance toward the antibiotics and, most importantly, the lifetime of the antibacterial activity offered by this strategy is limited. In this light, the development of adhesion resistant and especially of contact killing surfaces, with inherent antibacterial properties, has gained more and more interest in the biotechnology and biomaterial fields. In this light, in this review, we focused on chitosan as naturally-derived biocompatible antibacterial material for the development of surface coatings for pharmaceutical and biomedical applications.

Chitosan in fact, in addition to its intrinsic antimicrobial activity, features a series of beneficial properties for application in the biomedical field since it is highly biocompatible, non-immunogenic and non-allergenic, it is quite inexpensive and it can be easily processed in different forms such as gels, films, membranes, sponges, nanoparticles with tunable characteristics. On these premises chitosan has often been considered as the material of choice for the development of antibacterial coatings, not only in the biomedical field but also in food and textile industry.

Several strategies, involving adequate surface preparation followed by physiosorption or chemical grafting, can be exploited to produce chitosan-based coatings, generally on metal and polymeric surfaces, for a number of applications that range from dental implants to catheters, from orthopaedic prostheses to intraocular lens. However, it is difficult to identify general rules or coatings with superior "universal" properties since (i) many parameters, other than antibacterial efficiency, should be taken into account simultaneously (e.g., mechanical, physical and chemical stability, biodegradation rate, mechanical properties, thickness, morphology, etc.), (ii) the characteristics of the coating must be tailored and optimized to the specific application, and (iii) comparative studies are often missing, still making not clear how deposition techniques and chemical grafting can affect the antibacterial properties of the chitosan molecules. Furthermore, there is a general lack of information on the performance of chitosan antibacterial coatings in vivo, owing to the expensiveness of these tests, and currently employed in vitro experiments are performed in exemplified models that do not adequately mimic the huge number of factors acting in vivo (e.g., inflammation, $\mathrm{pH}$, presence of enzymes, adsorption of proteins, cyclic mechanical solicitations, etc.).

A more systematic research, involving both thorough material physicochemical characterization and biological evaluation, preferably also in vivo, would be necessary to draw reliable structureactivity relationships that could guide the design of chitosan antibacterial coatings optimized for the specific application. More standardized evaluation protocols would also be beneficial to allow the easier and trustworthy comparison among the results obtained across different laboratories.

Nevertheless, the positive results usually obtained by chitosan coatings against both Gram-positive and Gram-negative bacteria (and sometimes also against fungi), despite their known preferential bactericidal activity against Gram-positive cells, and their almost always demonstrated cytocompatibility are very promising cornerstones for the future translation into clinics of these technologies. In particular, multifunctional systems, combining different mechanisms of action against pathogens are emerging as the next generation chitosan-based coatings.

\section{CONSENT FOR PUBLICATION}

Not applicable.

\section{CONFLICT OF INTEREST}

The authors declare no conflict of interest, financial or otherwise.

\section{ACKNOWLEDGEMENTS}

JMV and CSC were awarded a doctoral scholarship by the National Council for Scientific and Technological Development (CNPq) -- Brazil. DP was awarded a post-doctoral scholarship from the NSERC CREATE Program in Regenerative Medicine (www.ncprm.ulaval.ca). This work was supported by CNPq, the Natural Sciences and Engineering Research Council of Canada (NSERC), the Canada Research Chair Tier I for the Innovation in Surgery, Fonds de recherche du Québec - Nature et technologies (FRQNT), Canada foundation for innovation (CFI), and the CHU de Québec Research Center.

\section{REFERENCES}

[1] Swartjes JJ, Sharma PK, van Kooten TG, et al. Current developments in antimicrobial surface coatings for biomedical applications. Curr Med Chem 2015; 22(18): 2116-29.

[2] Cloutier M, Mantovani D, Rosei F. Antibacterial coatings: Challenges, Perspectives, and opportunities. Trends Biotechnol 2015; 33(11): 637-52.

[3] Cheung RC, Ng TB, Wong JH, Chan WY. Chitosan: An update on potential biomedical and pharmaceutical applications. Mar Drugs 2015; 13(8): 5156-86.

[4] Luo C, Liu W, Luo B, et al. Antibacterial activity and cytocompatibility of chitooligosaccharide-modified polyurethane membrane via polydopamine adhesive layer. Carbohydr Polym 2017; 156: 235-43.

[5] Lin QK, Xu X, Wang Y, Wang B, Chen H. Antiadhesive and antibacterial polysaccharide multilayer as IOL coating for prevention of postoperative infectious endophthalmitis. Int J Polym Mater Polym Biomater 2017; 66: 97-104.

[6] Zheng D, Neoh KG, Shi Z, Kang ET. Assessment of stability of surface anchors for antibacterial coatings and immobilized growth factors on titanium. J Colloid Interface Sci 2013; 406: 238-46.

[7] Zhao L, Chu PK, Zhang Y, Wu Z. Antibacterial coatings on titanium implants. J Biomed Mater Res B Appl Biomater 2009; 91(1): 470-80.

[8] Martin HJ, Schulz KH, Bumgardner JD, Schneider JA. Enhanced bonding of chitosan to implant quality titanium via four treatment combinations. Thin Solid Films 2008; 516: 6277-86.

[9] Martin HJ, Schulz KH, Bumgardner JD, Walters KB. An XPS study on the attachment of triethoxsilylbutyraldehyde to two titanium surfaces as a way to bond chitosan. Appl Surf Sci 2008; 254: 4599-605.

[10] $\mathrm{Hu}$ X, Neoh KG, Shi Z, Kang ET, Poh C, Wang W. An in vitro assessment of titanium functionalized with polysaccharides conjugated with vascular endothelial growth factor for enhanced osseointegration and inhibition of bacterial adhesion. Biomaterials 2010; 31(34): 8854-63.

[11] Chua P-H, Neoh K-G, Kang E-T, Wang W. Surface functionalization of titanium with hyaluronic acid/chitosan polyelectrolyte multilayers and RGD for promoting osteoblast functions and inhibiting bacterial adhesion. Biomaterials 2008; 29(10): 1412-21.

[12] Ahmed RA, Fadl-Allah SA, El-Bagoury N, El-Rab SM. Improvement of corrosion resistance and antibacterial effect of NiTi orthopedic materials by chitosan and gold nanoparticles. Appl Surf Sci 2014; 292: 390-9.

[13] Li P, Zhang X, Xu R, et al. Electrochemically deposited chitosan/Ag complex coatings on biomedical NiTi alloy for antibacterial application. Surf Coat Tech 2013; 232: 370-5.

[14] Ferraris S, Spriano S. Antibacterial titanium surfaces for medical implants. Mater Sci Eng C 2016; 61: 965-78.

[15] Sutha S, Karunakaran G, Rajendran V. Enhancement of antimicrobial and long-term biostability of the zinc-incorporated hydroxyapatite coated $316 \mathrm{~L}$ stainless steel implant for biomedical application. Ceram Int 2013; 39: 5205-12.

[16] Umair MM, Jiang Z, Ullah N, Safdar W, Xie Z, Ren X. Development and characterisation of antibacterial suture functionalised with N-halamines. J Ind Text 2016; 46: 59-74. 
[17] Cado G, Aslam R, Séon L, et al. Self-defensive biomaterial coating against bacteria and yeasts: Polysaccharide multilayer film with embedded antimicrobial peptide. Adv Funct Mater 2013; 23: 48019.

[18] Tiller JC. Antimicrobial Surfaces. Adv Polym Sci 2010; 193-217.

[19] Costello EK, Lauber CL, Hamady M, Fierer N, Gordon JI, Knight R. Bacterial community variation in human body habitats across space and time. Science 2009; 326: 1694-97.

[20] Sender R, Fuchs S, Milo R. revised estimates for the number of human and bacteria cells in the body. PLoS Biol 2016; 14(8): e1002533.

[21] Lichter JA, Van Vliet KJ, Rubner MF. Design of antibacterial surfaces and interfaces: Polyelectrolyte multilayers as a multifunctional platform. Macromolecules 2009; 42: 8573-86.

[22] Trentin D da S, Giordani RB, Macedo AJ. Biofilmes bacterianos patogênicos: Aspectos gerais, importância clínica e estratégias de combate. Rev Lib 2013; 14: 113-238.

[23] Harvey RJ, Lund VJ. Biofilms and chronic rhinosinusitis: systematic review of evidence, current concepts and directions for research. Rhinology 2007; 45(1): 3-13.

[24] Pascual A. Pathogenesis of catheter-related infections: lessons for new designs. Clin Microbiol Infect 2002; 8(5): 256-64.

[25] Lappin-Scott HM, Costerton JW. Bacterial biofilms and surface fouling. Biofouling 1989; 1: 323-42.

[26] An YH, Friedman RJ. Concise review of mechanisms of bacterial adhesion to biomaterial surfaces. J Biomed Mater Res 1998; 43(3): 338-48.

[27] Hall-Stoodley L, Costerton JW, Stoodley P. Bacterial biofilms: from the natural environment to infectious diseases. Nat Rev Microbiol 2004; 2(2): 95-108.

[28] del Pozo JL, Patel R. The challenge of treating biofilm-associated bacterial infections. Clin Pharmacol Ther 2007; 82(2): 204-9.

[29] Herrmann M, Vaudaux PE, Pittet D, et al. Fibronectin, fibrinogen, and laminin act as mediators of adherence of clinical staphylococcal isolates to foreign material. J Infect Dis 1988; 158(4): 693-701.

[30] Norowski PA Jr, Bumgardner JD. Biomaterial and antibiotic strategies for peri-implantitis: A review. J Biomed Mater Res B Appl Biomater 2009; 88(2): 530-43.

[31] Katsikogianni M, Missirlis YF. Concise review of mechanisms of bacterial adhesion to biomaterials and of techniques used in estimating bacteria-material interactions. Eur Cell Mater 2004; 8: 3757.

[32] Kramer A, Schwebke I, Kampf G. How long do nosocomial pathogens persist on inanimate surfaces? A systematic review. BMC Infect Dis 2006; 6: 130 .

[33] Davies D. Understanding biofilm resistance to antibacterial agents. Nat Rev Drug Discov 2003; 2(2): 114-22.

[34] Costerton JW, Stewart PS, Greenberg EP. Bacterial biofilms: A common cause of persistent infections. Science (80- ) 1999; 284 : 1318-22.

[35] Vasilev K, Cook J, Griesser HJ. Antibacterial surfaces for biomedical devices. Expert Rev Med Devices 2009; 6(5): 553-67.

[36] Page K, Wilson M, Parkin IP. Antimicrobial surfaces and their potential in reducing the role of the inanimate environment in the incidence of hospital-acquired infections. J Mater Chem 2009; 19: 3819.

[37] Borkow G. Use of biocidal surfaces for reduction of healthcare acquired infections. Cham: Springer International Publishing 2014.

[38] MCKENNA M. The coming cost of superbugs: 10 million deaths per. 2014.Available from: https://www.wired.com/2014/12/oneillrpt-amr/\#slide-2

[39] Hernandez-Montelongo J, Lucchesi EG, Gonzalez I, et al. Hyaluronan/chitosan nanofilms assembled layer-by-layer and their antibacterial effect: A study using Staphylococcus aureus and Pseudomonas aeruginosa. Colloids Surf B Biointerfaces 2016; 141: 499-506

[40] World Health Organization. Report on the burden of endemic health-care associated infection worldwide-a systematic review of the literature. World Heal Organ Geneva 2011.

[41] Hensley BJ, Monson JR. Hospital-acquired infections. Surg 2015; 33: 528-33.

[42] Wenzel RP. Health care-associated infections: major issues in the early years of the 21 st century. Clin Infect Dis 2007; 45(Suppl. 1): S85-8.
[43] Li Z, Lee D, Sheng X, Cohen RE, Rubner MF. Two-level antibacterial coating with both release-killing and contact-killing Capabilities 2006; 22: 9820-3.

[44] Campoccia D, Montanaro L, Arciola CR. A review of the biomaterials technologies for infection-resistant surfaces. Biomaterials 2013; 34(34): 8533-54

[45] Rubino C, Brongo S, Pagliara D, et al. Infections in breast implants: A review with a focus on developing countries. J Infect Dev Ctries 2014; 8(9): 1089-95.

[46] Klug D, Lacroix D, Savoye C, et al. Systemic infection related to endocarditis on pacemaker leads: clinical presentation and management. Circulation 1997; 95(8): 2098-107.

[47] Lynch AS, Robertson GT. Bacterial and fungal biofilm infections. Annu Rev Med 2008; 59: 415-28.

[48] Tawfik KO, Golub JS, Roland JT, Samy RN. Recurrent cochlear implant infection treated with exteriorization and partial mastoid obliteration. Cochlear Implants Int 2016; 17(1): 58-61.

[49] Willcox MD, Harmis N, Cowell BA, Williams T, Holden BA. Bacterial interactions with contact lenses; effects of lens material, lens wear and microbial physiology. Biomaterials 2001; 22(24) 3235-47.

[50] Ducasse E, Calisti A, Speziale F, Rizzo L, Misuraca M, Fiorani P. Aortoiliac stent graft infection: current problems and management. Ann Vasc Surg 2004; 18(5): 521-6.

[51] Lichtenfels E, Frankini AD, Cardozo MA, D’Azevedo PA. Stent graft infection. J Vasc Bras 2011; 10: 50-4.

[52] Parkunan SM, Callegan MC. The pathogenesis of bacterial endophthalmitis. Endophthalmitis.; Cham: Springer International Publishing 2016; pp. 17-47.

[53] Sala-Pérez S, López-Ramírez M, Quinteros-Borgarello M, Valmaseda-Castellón E, Gay-Escoda C. Antibacterial suture vs silk for the surgical removal of impacted lower third molars. A randomized clinical study. Med Oral Patol Oral Cir Bucal 2016; 21(1): e95e102.

[54] Henry-Stanley MJ, Hess DJ, Barnes AM, Dunny GM, Wells CL. Bacterial contamination of surgical suture resembles a biofilm. Surg Infect (Larchmt) 2010; 11(5): 433-9.

[55] Nicolle LE. Catheter associated urinary tract infections. Antimicrob Resist Infect Control 2014; 3: 23.

[56] Moriarty TF, Poulsson AH, Rochford ET, Richards RG. Bacterial adhesion and biomaterial surfaces. In: Ducheyne P, Ed. Compr. Biomater. 1st ed.; Elsevier 2011; pp. 75-100.

[57] Dee KC. Puleo D A, Bizios R. An introduction to tissuebiomaterial interactions 1 st ed. 1st ed.2002.

[58] Siedenbiedel F, Tiller JC. Antimicrobial polymers in solution and on surfaces: Overview and functional principles. Polymers (Basel) 2012; 4: 46-71.

[59] Tiller JC, Liao C-J, Lewis K, Klibanov AM. Designing surfaces that kill bacteria on contact. Proc Natl Acad Sci USA 2001; 98(11): 5981-5.

[60] Noda Y, Kanemasa Y. Determination of hydrophobicity on bacterial surfaces by nonionic surfactants. J Bacteriol 1986; 167(3): 1016-9.

[61] Yuan S, Yin J, Jiang W, Liang B, Pehkonen SO, Choong C. Enhancing antibacterial activity of surface-grafted chitosan with immobilized lysozyme on bioinspired stainless steel substrates. Colloids Surf B Biointerfaces 2013; 106: 11-21.

[62] Fu J, Ji J, Yuan W, Shen J. Construction of anti-adhesive and antibacterial multilayer films via layer-by-layer assembly of heparin and chitosan. Biomaterials 2005; 26(33): 6684-92.

[63] Ivanova NA, Philipchenko AB. Superhydrophobic chitosan-based coatings for textile processing. Appl Surf Sci 2012; 263: 783-7.

[64] Ravi Kumar MN. A review of chitin and chitosan applications. React Funct Polym 2000; 46: 1-27.

[65] Yao K, Li J, Yao F, Yin Y. Chitosan-based hydrogels: Functions and Applications. CRC Press 2011.

[66] Branconnot H. Recherches analytiques sur la nature des champignons. Ann Chim 1811; 79: 265-304.

[67] Rouget C. Des substances amylacées dans les tissus des animaux, spécialement des Articulés (chitine). Comptes rendus Hebd des séances 1 â€TM Académie des Sci 1859; 48: 792-95.

[68] Rinaudo M. Chitin and chitosan: Properties and applications. Prog Polym Sci 2006; 31: 603-32.

[69] Croisier F, Jérôme C. Chitosan-based biomaterials for tissue engineering. Eur Polym J 2013; 49: 780-92. 
[70] Vaz JM, Michel EC, Chevallier P, Beppu MM, Mantovani D. Covalent grafting of chitosan on plasma-treated polytetrafluoroethylene surfaces for biomedical applications. J Biomater Tissue Eng 2014; 4: 915-24.

[71] Singla AK, Chawla M. Chitosan: some pharmaceutical and biological aspects--an update. J Pharm Pharmacol 2001; 53(8): 104767.

[72] Mourya VK, Inamdar NN. Chitosan-modifications and applications: Opportunities galore. React Funct Polym 2008; 68: 1013-51.

[73] VandeVord PJ, Matthew HW, DeSilva SP, Mayton L, Wu B, Wooley PH. Evaluation of the biocompatibility of a chitosan scaffold in mice. J Biomed Mater Res 2002; 59(3): 585-90.

[74] Ogawa K, Yui T. Crystallinity of partially N-acetylated chitosans. Biosci Biotechnol Biochem 1993; 57: 1466-9.

[75] Rabea EI, Badawy ME, Stevens CV, Smagghe G, Steurbaut W. Chitosan as antimicrobial agent: Applications and mode of action. Biomacromolecules 2003; 4(6): 1457-65.

[76] Chen RH, Tsaih ML. Effect of temperature on the intrinsic viscosity and conformation of chitosans in dilute $\mathrm{HCl}$ solution. Int J Biol Macromol 1998; 23(2): 135-41.

[77] Foster LJ, Ho S, Hook J, Basuki M, Marçal H. Chitosan as a biomaterial: Influence of degree of deacetylation on its physiochemical, material and biological properties. PLoS One 2015; 10(8): e0135153.

[78] Berger J, Reist M, Mayer JM, Felt O, Gurny R. Structure and interactions in chitosan hydrogels formed by complexation or aggregation for biomedical applications. Eur J Pharm Biopharm 2004; 57(1): 35-52.

[79] Vallières K, Petitclerc E, Laroche G. Covalent grafting of fibronectin onto plasma-treated PTFE: influence of the conjugation strategy on fibronectin biological activity. Macromol Biosci 2007; 7(5): 738-45.

[80] Cheng CY, Li YK. An Aspergillus chitosanase with potential for large-scale preparation of chitosan oligosaccharides. Biotechnol Appl Biochem 2000; 32(Pt 3): 197-203.

[81] Dash M, Chiellini F, Ottenbrite RM, Chiellini E. Chitosan - A versatile semi-synthetic polymer in biomedical applications. Prog Polym Sci 2011; 36: 981-1014.

[82] Ren D, Yi H, Wang W, Ma X. The enzymatic degradation and swelling properties of chitosan matrices with different degrees of $\mathrm{N}$-acetylation. Carbohydr Res 2005; 340(15): 2403-10.

[83] Braz L, Rodrigues S, Fonte P, Grenha A, Sarmento B. Mechanisms of chemical and enzymatic chitosan biodegradability and its application on drug delivery. In: Felton GP, Ed. Biodegrad. Polym. Process. Degrad. Appl.; Nova Science Publishers 2011; pp. 325-64.

[84] Rodrigues S, Dionísio M, López CR, Grenha A. Biocompatibility of chitosan carriers with application in drug delivery. J Funct Biomater 2012; 3(3): 615-41.

[85] Kean T, Thanou M. Biodegradation, biodistribution and toxicity of chitosan. Adv Drug Deliv Rev 2010; 62(1): 3-11.

[86] Bumgardner JD, Murali VP, Su H, et al. Characterization of chitosan matters. In: Jennings JA, Bumgardner JD, Eds. Chitosan Based Biomater. Vol. 1.; Elsevier 2017; pp. 81-114.

[87] Junginer H, Sadeghi A. Synthesis, Characterization and biomedical applications of chitosan and its derivatives. Chitin Chitosan Deriv.; CRC Press 2013; pp. 15-68.

[88] El-tahlawy El. bendary, M., Hudson, S. KF. The antimicrobial activity of cotton fabrics treated with different crosslinking agents and chitosan $\backslash$. Carbohydr Polym 2005; 60: 421-30.

[89] Campelo CS, Lima LD, Rebêlo LM, Mantovani D, Beppu MM, Vieira RS. In vitro evaluation of anti-calcification and anticoagulation on sulfonated chitosan and carrageenan surfaces. Mater Sci Eng C 2016; 59: 241-8.

[90] Campelo CS, Chevallier P, Vaz JM, Vieira RS, Mantovani D. Sulfonated chitosan and dopamine based coatings for metallic implants in contact with blood. Mater Sci Eng C 2017; 72: 682-91.

[91] Babel S, Kurniawan TA. Low-cost adsorbents for heavy metals uptake from contaminated water: A review. J Hazard Mater 2003; 97(1-3): 219-43.

[92] Mourya VK, Inamdar NN, Choudhari YM. Chitooligosaccharides: Synthesis, characterization and applications. Polym Sci Ser A 2011; 53: 583-612.

[93] Kurita K. Chemistry and application of chitin and chitosan. Polym Degrad Stabil 1998; 59: 117-20.

[94] Tikhonov VE, Stepnova EA, Babak VG, et al. Bactericidal and antifungal activities of a low molecular weight chitosan and its $\mathrm{N}$ - /2(3)-(dodec-2-enyl)succinoyl/-derivatives. Carbohydr Polym 2006; 64: 66-72.

[95] No HK, Park NY, Lee SH, Meyers SP. Antibacterial activity of chitosans and chitosan oligomers with different molecular weights. Int J Food Microbiol 2002; 74(1-2): 65-72.

[96] Terbojevich M, Cosani A, Muzzarelli RA. Molecular parameters of chitosans depolymerized with the aid of papain. Carbohydr Polym 1996; 29: 63-8

[97] Kong M, Chen XG, Xing K, Park HJ. Antimicrobial properties of chitosan and mode of action: A state of the art review. Int J Food Microbiol 2010; 144(1): 51-63.

[98] Devlieghere F, Vermeulen A, Debevere J. Chitosan: Antimicrobial activity, interactions with food components and applicability as a coating on fruit and vegetables. Food Microbiol 2004; 21: 703-14.

[99] Harish Prashanth KV, Tharanathan RN. Chitin/chitosan: modifications and their unlimited application potential - an overview. Trends Food Sci Technol 2007; 18: 117-31.

[100] Hirano S, Nagao N. Effects of chitosan, pectic acid, lyzosyme and chitinase on the growth of several phytopathogens. Agric Biol Chem 1989; 53: 3065-6.

[101] Durango AM, Soares NF, Benevides S, et al. Development and evaluation of an edible antimicrobial film based on yam starch and chitosan. Packag Technol Sci 2006; 19: 55-9.

[102] Smith A, Perelman M, Hinchcliffe M. Chitosan: A promising safe and immune-enhancing adjuvant for intranasal vaccines. Hum Vaccin Immunother 2014; 10(3): 797-807.

[103] Baldrick P. The safety of chitosan as a pharmaceutical excipient. Regul Toxicol Pharmacol 2010; 56(3): 290-9.

[104] Thanou M, Verhoef JC, Junginger HE. Oral drug absorption enhancement by chitosan and its derivatives. Adv Drug Deliv Rev 2001; 52(2): 117-26.

[105] Illum L. Chitosan and its use as a pharmaceutical excipient. Pharm Res 1998; 15(9): 1326-31.

[106] Wedmore I, McManus JG, Pusateri AE, Holcomb JB. A special report on the chitosan-based hemostatic dressing: experience in current combat operations. J Trauma 2006; 60(3): 655-8.

[107] Maeda M, Murakami H, Ohta H, Tajima M. Stimulation of IgM production in human-human hybridoma HB4C5 cells by chitosan. Biosci Biotechnol Biochem 1992; 56(3): 427-31.

[108] Muzzarelli RA. Chitins and chitosans as immunoadjuvants and non-allergenic drug carriers. Mar Drugs 2010; 8(2): 292-312.

[109] Gray HC, Hutcheson PS, Slavin RG. Is glucosamine safe in patients with seafood allergy? J Allergy Clin Immunol 2004; 114(2): 459-60.

[110] Villacis J, Rice TR, Bucci LR, et al. Do shrimp-allergic individuals tolerate shrimp-derived glucosamine? Clin Exp Allergy 2006; 36(11): 1457-61.

[111] Waibel KH, Haney B, Moore M, Whisman B, Gomez R. Safety of chitosan bandages in shellfish allergic patients. Mil Med 2011; 176(10): 1153-6.

[112] Ohe T. Antigenotoxic activities of chitin and chitosan as assayed by sister chromatid exchange. Sci Total Environ 1996; 181(1): 1-5.

[113] Koide SS. Chitin-chitosan: Properties, benefits and risks. Nutr Res 1998; 18: 1091-101.

[114] Muzzarelli RA, Zucchini C, Ilari P, et al. Osteoconductive properties of methylpyrrolidinone chitosan in an animal model. Biomaterials 1993; 14(12): 925-9.

[115] Zhou H, Qian J, Wang J, et al. Enhanced bioactivity of bone morphogenetic protein-2 with low dose of 2-N, 6-O-sulfated chitosan in vitro and in vivo. Biomaterials 2009; 30(9): 1715-24.

[116] Jia Z, shen D, Xu W. Synthesis and antibacterial activities of quaternary ammonium salt of chitosan. Carbohydr Res 2001; 333(1): $1-6$.

[117] Don TM, King CF, Chiu WY, Peng CA. Preparation and characterization of chitosan-g-poly(vinyl alcohol)/poly(vinyl alcohol) blends used for the evaluation of blood-contacting compatibility. Carbohydr Polym 2006; 63: 331-9.

[118] Balan V, Verestiuc L. Strategies to improve chitosan hemocompatibility: A review. Eur Polym J 2014; 53: 171-88.

[119] Xiong WY, Yi Y, Liu HZ, Wang H, Liu JH, Ying GQ. Selective carboxypropionylation of chitosan: synthesis, characterization, blood compatibility, and degradation. Carbohydr Res 2011; 346(10): 1217-23.

[120] Chan P, Kurisawa M, Chung JE, Yang YY. Synthesis and characterization of chitosan-g-poly(ethylene glycol)-folate as a non-viral 
carrier for tumor-targeted gene delivery. Biomaterials 2007; 28(3): 540-9.

[121] Liu XF, Guan YL, Yang DZ, Li Z, Yao KD. Antibacterial action of chitosan and carboxymethlyated chitosan. J Appl Polym Sci 2000; 79: $1324-35$

[122] Tiera MJ, Qiu XP, Bechaouch S, Shi Q, Fernandes JC, Winnik FM. Synthesis and characterization of phosphorylcholine-substituted chitosans soluble in physiological $\mathrm{pH}$ conditions. Biomacromolecules 2006; 7(11): 3151-6.

[123] Wang Z, Zeng R, Tu M, Zhao J. A novel biomimetic chitosanbased nanocarrier with suppression of the protein-nanocarrier interactions. Mater Lett 2012; 77: 38-40.

[124] Tardif K, Cloutier I, Miao Z, et al. A phosphorylcholine-modified chitosan polymer as an endothelial progenitor cell supporting matrix. Biomaterials 2011; 32(22): 5046-55.

[125] Aiping Z, Tian C. Blood compatibility of surface-engineered poly(ethylene terephthalate) via o-carboxymethylchitosan. Colloids Surf B Biointerfaces 2006; 50(2): 120-5.

[126] Xin Z, Hou J, Ding J, Yang Z, Yan S, Liu C. Surface functionalization of polyethylene via covalent immobilization of O-stearoylchitosan. Appl Surf Sci 2013; 279: 424-31.

[127] Davidovich-Pinhas M, Danin-Poleg Y, Kashi Y, Bianco-Peled H. Modified chitosan: A step toward improving the properties of antibacterial food packages. Food Packag Shelf Life 2014; 1: 160-9.

[128] Aytekin AO, Morimura S, Kida K. Synthesis of chitosan-caffeic acid derivatives and evaluation of their antioxidant activities. J Biosci Bioeng 2011; 111(2): 212-6.

[129] Vikhoreva G, Bannikova G, Stolbushkina P, et al. Preparation and anticoagulant activity of a low-molecular-weight sulfated chitosan. Carbohydr Polym 2005; 62: 327-32.

[130] Zhang C, Ping Q, Zhang H, Shen J. Preparation of N-alkyl-Osulfate chitosan derivatives and micellar solubilization of taxol. Carbohydr Polym 2003; 54: 137-41.

[131] Sharma RK, Lalita, Singh AP, Chauhan GS. Grafting of GMA and some comonomers onto chitosan for controlled release of diclofenac sodium. Int J Biol Macromol 2014; 64: 368-76.

[132] Al Sagheer FA, Khalil KD, Ibrahim EI. Synthesis and characterization of chitosan-g-poly(2-(furan-2-carbonyl)- acrylonitrile): Grafting of chitosan using a novel monomer prepared by a BaylisHillman reaction. Eur Polym J 2013; 49: 1662-72.

[133] Muzzarelli RA, Mattioli-Belmonte M, Tietz C, et al. Stimulatory effect on bone formation exerted by a modified chitosan. Biomaterials $1994 ; 15(13)$ : 1075-81.

[134] Pillai CK, Paul W, Sharma CP. Chitin and chitosan polymers: Chemistry, solubility and fiber formation. Prog Polym Sci 2009; 34: $641-78$.

[135] Le Tien C, Lacroix M, Ispas-Szabo P, Mateescu MA. N-acylated chitosan: hydrophobic matrices for controlled drug release. J Control Release 2003; 93(1): 1-13.

[136] Boucard N, Viton C, Agay D, et al. The use of physical hydrogels of chitosan for skin regeneration following third-degree burns. Biomaterials 2007; 28(24): 3478-88.

[137] Li XQ, Tang RC. Crosslinking of chitosan fiber by a water-soluble diepoxy crosslinker for enhanced acid resistance and its impact on fiber structures and properties. React Funct Polym 2016; 100: 11622 .

[138] Zhang J, Lu X, Feng G, et al. Chitosan scaffolds induce human dental pulp stem cells to neural differentiation: potential roles for spinal cord injury therapy. Cell Tissue Res 2016; 366(1): 129-42.

[139] Qi L, Xu Z, Jiang X, Hu C, Zou X. Preparation and antibacterial activity of chitosan nanoparticles. Carbohydr Res 2004; 339(16): 2693-700.

[140] Bégin A, Van Calsteren MR. Antimicrobial films produced from chitosan. Int J Biol Macromol 1999; 26(1): 63-7.

[141] Tang C, Zhang Q, Wang K, Fu Q, Zhang C. Water transport behavior of chitosan porous membranes containing multi-walled carbon nanotubes (MWNTs). J Membr Sci 2009; 337: 240-7.

[142] Beppu MM, Vieira RS, Aimoli CG, Santana CC. Crosslinking of chitosan membranes using glutaraldehyde: Effect on ion permeability and water absorption. J Membr Sci 2007; 301: 126-30.

[143] Khor E, Lim LY. Implantable applications of chitin and chitosan. Biomaterials 2003; 24(13): 2339-49.

[144] Raafat D, Sahl HG. Chitosan and its antimicrobial potential--a critical literature survey. Microb Biotechnol 2009; 2(2): 186-201.
[145] Nunthanid J, Laungtana-Anan M, Sriamornsak $\mathrm{P}$, et al. Characterization of chitosan acetate as a binder for sustained release tablets. J Control Release 2004; 99(1): 15-26.

[146] Hino T, Kawashima Y, Shimabayashi S. Basic study for stabilization of $\mathrm{w} / \mathrm{o} / \mathrm{w}$ emulsion and its application to transcatheter arterial embolization therapy. Adv Drug Deliv Rev 2000; 45(1): 27-45.

[147] Vishu Kumar AB, Varadaraj MC, Gowda LR, Tharanathan RN. Characterization of chito-oligosaccharides prepared by chitosanolysis with the aid of papain and Pronase, and their bactericidal action against Bacillus cereus and Escherichia coli. Biochem J 2005; 391(Pt 2): 167-75.

[148] Park P-J, Je J-Y, Jung W-K, Ahn C-B, Kim S-K. Anticoagulant activity of heterochitosans and their oligosaccharide sulfates. Eur Food Res Technol 2004; 219: 529-33.

[149] Kawase T, Sawada H. End-capped fluoroalkyl-functional silanes. Part II: Modification of polymers and possibility of multifunctional silanes. J Adhes Sci Technol 2002; 16: 1121-40.

[150] Pezzoli D, Chiesa R, De Nardo L, Candiani G. We still have a long way to go to effectively deliver genes! J Appl Biomater Funct Mater 2012; 10(2): 82-91.

[151] Kofuji K, Qian C-J, Nishimura M, Sugiyama I, Murata Y, Kawashima S. Relationship between physicochemical characteristics and functional properties of chitosan. Eur Polym J 2005; 41: 2784-91.

[152] Mitra A, Dey B. Chitosan microspheres in novel drug delivery systems. Indian J Pharm Sci 2011; 73(4): 355-66.

[153] Ahmadi F, Oveisi Z, Samani SM, Amoozgar Z. Chitosan based hydrogels: characteristics and pharmaceutical applications. Res Pharm Sci 2015; 10(1): 1-16.

[154] Nie J, Wang Z, Hu Q. Difference between Chitosan Hydrogels via Alkaline and Acidic Solvent Systems. Sci Rep 2016; 6: 36053.

[155] Giri TK, Thakur A, Alexander A. Ajazuddin, Badwaik H, Tripathi DK. Modified chitosan hydrogels as drug delivery and tissue engineering systems: present status and applications. Acta Pharm Sin B 2012; 2: 439-49.

[156] Assaad E, Maire M, Lerouge S. Injectable thermosensitive chitosan hydrogels with controlled gelation kinetics and enhanced mechanical resistance. Carbohydr Polym 2015; 130: 87-96.

[157] Zhou HY, Jiang LJ, Cao PP, Li JB, Chen XG. Glycerophosphatebased chitosan thermosensitive hydrogels and their biomedical applications. Carbohydr Polym 2015; 117: 524-36

[158] Zhang N, Wardwell PR, Bader RA. Polysaccharide-based micelles for drug delivery. Pharmaceutics 2013; 5(2): 329-52.

[159] Riva R, Ragelle H, des Rieux A, Duhem N, Jérôme C, Préat V. Chitosan and chitosan derivatives in drug delivery and tissue engineering. Adv Polym Sci 2011; 19-44.

[160] Pezzoli D, Candiani G. Non-viral gene delivery strategies for gene therapy: A "ménage à trois" among nucleic acids, materials, and the biological environment. J Nanopart Res 2013; 15: 1523.

[161] Jean M, Smaoui F, Lavertu M, et al. Chitosan-plasmid nanoparticle formulations for IM and SC delivery of recombinant FGF-2 and PDGF-BB or generation of antibodies. Gene Ther 2009; 16(9): 1097-110.

[162] Han HD, Mangala LS, Lee JW, et al. Targeted gene silencing using RGD-labeled chitosan nanoparticles. Clin Cancer Res 2010 16(15): 3910-22.

[163] Pezzoli D, Olimpieri F, Malloggi C, Bertini S, Volonterio A, Candiani G. Chitosan-graft-branched polyethylenimine copolymers: influence of degree of grafting on transfection behavior. PLoS One 2012; 7(4): e34711.

[164] Safari S, Zarrintan MH, Soleimani M, et al. Evaluation and optimization of chitosan derivatives-based gene delivery system via kidney epithelial cells. Adv Pharm Bull 2012; 2(1): 7-16.

[165] Choi B, Kim S, Lin B, Wu BM, Lee M. Cartilaginous extracellular matrix-modified chitosan hydrogels for cartilage tissue engineering. ACS Appl Mater Interfaces 2014; 6(22): 20110-21.

[166] Ng WL, Yeong WY, Naing MW. Development of polyelectrolyte chitosan-gelatin hydrogels for skin bioprinting. Procedia CIRP 2016; 49: 105-12.

[167] Vrana NE, Liu Y, McGuinness GB, Cahill PA. Characterization of poly(vinyl alcohol)/chitosan hydrogels as vascular tissue engineering scaffolds. Macromol Symp 2008; 269: 106-10.

[168] Gnavi S, Barwig C, Freier T, Haastert-Talini K, Grothe C, Geuna $\mathrm{S}$. The use of chitosan-based scaffolds to enhance regeneration in the nervous system. Int Rev Neurobiol 2013; 109: 1-62.

[169] Ahmed S, Ikram S. chitosan based scaffolds and their applications in wound healing. Achiev Life Sci 2016; 10: 27-37. 
[170] Dai T, Tanaka M, Huang Y-Y, Hamblin MR. Chitosan preparations for wounds and burns: Antimicrobial and wound-healing effects. Expert Rev Anti Infect Ther 2011; 9(7): 857-79.

[171] Goddard JM, Hotchkiss JH. Polymer surface modification for the attachment of bioactive compounds. Prog Polym Sci 2007; 32: 698725 .

[172] Berger J, Reist M, Mayer JM, Felt O, Peppas NA, Gurny R. Structure and interactions in covalently and ionically crosslinked chitosan hydrogels for biomedical applications. Eur J Pharm Biopharm 2004; 57(1): 19-34.

[173] Michel EC, Montaño-Machado V, Chevallier P, Labbé-Barrère A, Letourneur D, Mantovani D. Dextran grafting on PTFE surface for cardiovascular applications. Biomatter 2014; 4: e28805.

[174] Kim SE, Song SH, Yun YP, et al. The effect of immobilization of heparin and bone morphogenic protein-2 (BMP-2) to titanium surfaces on inflammation and osteoblast function. Biomaterials 2011; 32(2): 366-73.

[175] Wiacek AE, Terpiłowski K, Jurak M, Worzakowska M. Lowtemperature air plasma modification of chitosan-coated PEEK biomaterials. Polym Test 2016; 50: 325-34.

[176] Avetta P, Nisticò R, Faga MG, et al. Hernia-repair prosthetic devices functionalised with chitosan and ciprofloxacin coating: controlled release and antibacterial activity. J Mater Chem B Mater Biol Med 2014; 2: 5287.

[177] Stoleru E, Munteanu SB, Dumitriu RP, et al. Polyethylene materials with multifunctional surface properties by electrospraying chitosan/vitamin E formulation destined to biomedical and food packaging applications. Iran Polym J (English Ed 2016; 25: 295-307.

[178] Chen X, Cai K, Fang J, et al. Fabrication of selenium-deposited and chitosan-coated titania nanotubes with anticancer and antibacterial properties. Colloids Surf B Biointerfaces 2013; 103: 149-57.

[179] Bulwan M, Wójcik K, Zapotoczny S, Nowakowska M. Chitosanbased ultrathin films as antifouling, anticoagulant and antibacterial protective coatings. J Biomater Sci Polym Ed 2012; 23(15): 196380.

[180] Xu X, Wang L, Guo S, Lei L, Tang T. Surface chemical study on the covalent attachment of hydroxypropyltrimethyl ammonium chloride chitosan to titanium surfaces. Appl Surf Sci 2011; 257: 10520-8.

[181] Mitra D, Li M, Wang R, Tang Z, Kang ET, Neoh KG. Scalable aqueous-based process for coating polymer and metal substrates with stable quaternized chitosan antibacterial coatings. Ind Eng Chem Res 2016; 55: 9603-13.

[182] Almodóvar J, Mower J, Banerjee A, Sarkar AK, Ehrhart NP, Kipper MJ. Chitosan-heparin polyelectrolyte multilayers on cortical bone: periosteum-mimetic, cytophilic, antibacterial coatings. Biotechnol Bioeng 2013; 110(2): 609-18.

[183] Yuan S, Li Z, Zhao J, et al. Enhanced biocompatibility of biostable poly(styrene-b-isobutylene-b-styrene) elastomer via poly(dopamine)-assisted chitosan/hyaluronic acid immobilization. RSC Advances 2014; 4: 31481.

[184] Renoud P, Toury B, Benayoun S, Attik G, Grosgogeat B. Functionalization of titanium with chitosan via silanation: evaluation of biological and mechanical performances. PLoS One 2012; 7(7): e39367.

[185] Greene AH, Bumgardner JD, Yang Y, Moseley J, Haggard WO. Chitosan-coated stainless steel screws for fixation in contaminated fractures. Clin Orthop Relat Res 2008; 466(7): 1699-704.

[186] Lv W, Luo J, Deng Y, Sun Y. Biomaterials immobilized with chitosan for rechargeable antimicrobial drug delivery. J Biomed Mater Res A 2013; 101(2): 447-55.

[187] Della Valle C, Visai L, Santin M, et al. A novel antibacterial modification treatment of titanium capable to improve osseointegration. Int J Artif Organs 2012; 35(10): 864-75.

[188] Bazaka K, Jacob MV, Crawford RJ, Ivanova EP. Plasma-assisted surface modification of organic biopolymers to prevent bacterial attachment. Acta Biomater 2011; 7(5): 2015-28.

[189] Ogino A, Kral M, Yamashita M, Nagatsu M. Effects of lowtemperature surface-wave plasma treatment with various gases on surface modification of chitosan. Appl Surf Sci 2008; 255: 234752.

[190] Theapsak S, Watthanaphanit A, Rujiravanit R. Preparation of chitosan-coated polyethylene packaging films by DBD plasma treatment. ACS Appl Mater Interfaces 2012; 4(5): 2474-82.
[191] Massines F, Gherardi N, Fornelli A, Martin S. Atmospheric pressure plasma deposition of thin films by Townsend dielectric barrier discharge. Surf Coat Tech 2005; 200: 1855-61.

[192] Fanelli F. Thin film deposition and surface modification with atmospheric pressure dielectric barrier discharges. Surf Coat Tech 2010; 205: 1536-43.

[193] Silva SS, Luna SM, Gomes ME, et al. Plasma surface modification of chitosan membranes: characterization and preliminary cell response studies. Macromol Biosci 2008; 8(6): 568-76.

[194] Stoleru E, Dumitriu RP, Munteanu BS, et al. Novel procedure to enhance PLA surface properties by chitosan irreversible immobilization. Appl Surf Sci 2016; 367: 407-17.

[195] Kohri M, Nannichi Y, Kohma H, et al. Size control of polydopamine nodules formed on polystyrene particles during dopamine polymerization with carboxylic acid-containing compounds for the fabrication of raspberry-like particles. Colloids Surfaces A Physicochem Eng Asp 2014; 449: 114-20.

[196] Saidin S, Chevallier P, Abdul Kadir MR, Hermawan H, Mantovani D. Polydopamine as an intermediate layer for silver and hydroxyapatite immobilisation on metallic biomaterials surface. Mater Sci Eng C 2013; 33(8): 4715-24.

[197] Ge B, Tan Y, Xie Q, Ma M, Yao S. Preparation of chitosandopamine-multiwalled carbon nanotubes nanocomposite for electrocatalytic oxidation and sensitive electroanalysis of NADH. Sens Actuators B Chem 2009; 137: 547-54.

[198] Bauer S, Schmuki P, von der Mark K, Park J. Engineering biocompatible implant surfaces. Prog Mater Sci 2013; 58: 261-326.

[199] Sulek F, Milosev I. inhibitory effects of chitosan coating against biofilm formation on metal implants. In: S. Passamonti, S. Gustincich, T. Lah Turnšek, B. Peterlin, R. Pišot PS, Ed. Cross-border Italy-Slovenia Biomed. Res. Are we ready Horiz. 2020?; 2014; pp. 133-38.

[200] Venkatrajah B, Malathy VV, Elayarajah B, Rajendran R, Rammohan R. Synthesis of carboxymethyl chitosan and coating on wound dressing gauze for wound healing. Pak J Biol Sci 2013; 16(22): 1438-48.

[201] Yang Y, Yang S, Wang Y, Zhang S, Yu Z, Tang T. Bacterial inhibition potential of quaternised chitosan-coated VICRYL absorbable suture: An in vitro and in vivo study. J Orthop Transl 2017; 8: 4961.

[202] Pütz J, Aegerter M, Guzman G. Sol-gel coating of thin display glasses-problems and remedy. Sol-Gel Sci Technol 2004; 32: 1259.

[203] Boulmedais F, Frisch B, Etienne O, et al. Polyelectrolyte multilayer films with pegylated polypeptides as a new type of antimicrobial protection for biomaterials. Biomaterials 2004; 25(11): 2003-11.

[204] Wang BL, Wang JL, Li DD, Ren KF, Ji J. Chitosan/poly (vinyl pyrollidone) coatings improve the antibacterial properties of poly(ethylene terephthalate). Appl Surf Sci 2012; 258: 7801-8.

[205] Yilmaz Atay H, Çelik E. Investigations of antibacterial activity of chitosan in the polymeric composite coatings. Prog Org Coat 2017; 102: 194-200.

[206] Ignatova M, Manolova N, Rashkov I, Markova N. Quaternized chitosan/ $\kappa$-carrageenan/caffeic acid-coated poly(3hydroxybutyrate) fibrous materials: Preparation, antibacterial and antioxidant activity. Int J Pharm 2016; 513(1-2): 528-37.

[207] Decher G. Fuzzy Nanoassemblies: Toward Layered Polymeric Multicomposites. Science (80- ) 1997; 277: 1232-37.

[208] Decher G, Hong JD, Schmitt J. Buildup of ultrathin multilayer films by a self-assembly process: III. Consecutively alternating adsorption of anionic and cationic polyelectrolytes on charged surfaces. Thin Solid Films 1992; 210-211: 831-5.

[209] Lowack K, Helm CA. Molecular mechanisms controlling the selfassembly process of polyelectrolyte multilayers. Macromolecules 1998; 31: 823-33.

[210] Richert L, Lavalle P, Payan E, et al. Layer by layer buildup of polysaccharide films: physical chemistry and cellular adhesion aspects. Langmuir 2004; $20(2)$ : 448-58.

[211] Vasconcellos F da C. Production of biopolymer nanostructures through layer-by-layer deposition with antibacterial and lymphocyte immobilization properties. State University of São Paulo, 2011.

[212] Krogman KC, Lowery JL, Zacharia NS, Rutledge GC, Hammond PT. Spraying asymmetry into functional membranes layer-by-layer. Nat Mater 2009; 8(6): 512-8. 
[213] Izquierdo A, Ono SS, Voegel J-C, Schaaf P, Decher G. Dipping versus spraying: exploring the deposition conditions for speeding up layer-by-layer assembly. Langmuir 2005; 21(16): 7558-67.

[214] Nogueira GM, Banerjee D, Cohen RE, Rubner MF. Spray-layerby-layer assembly can more rapidly produce optical-quality multistack Heterostructures 2011; 27: 7860-7.

[215] Krebs FC. Fabrication and processing of polymer solar cells: A review of printing and coating techniques. Sol Energy Mater Sol Cells 2009; 93: 394-412.

[216] Sutha S, Kavitha K, Karunakaran G, Rajendran V. In-vitro bioactivity, biocorrosion and antibacterial activity of silicon integrated hydroxyapatite/chitosan composite coating on $316 \mathrm{~L}$ stainless steel implants. Mater Sci Eng C 2013; 33(7): 4046-54.

[217] Guo Q, Mather JP, Yang P, Boden M, Mather PT. Fabrication of polymeric coatings with controlled microtopographies using an electrospraying technique. PLoS One 2015; 10(6): e0129960.

[218] Zhitomirsky I, Hashambhoy A. Chitosan-mediated electrosynthesis of organic-inorganic nanocomposites. J Mater Process Technol 2007; 191: 68-72.

[219] Geng Z, Wang X, Guo X, Zhang Z, Chen Y, Wang Y. Electrodeposition of chitosan based on coordination with metal ions in situgenerated by electrochemical oxidation. J Mater Chem B Mater Biol Med 2016; 4: 3331-8

[220] Ordikhani F, Tamjid E, Simchi A. Characterization and antibacterial performance of electrodeposited chitosan-vancomycin compos- ite coatings for prevention of implant-associated infections. Mater Sci Eng C 2014; 41: 240-8.

[221] Seuss S, Lehmann M, Boccaccini AR. Alternating current electrophoretic deposition of antibacterial bioactive glass-chitosan composite coatings. Int J Mol Sci 2014; 15(7): 12231-42.

[222] Jayakumar R, Prabaharan M, Reis RL, Mano JF. Graft copolymerized chitosan - Present status and applications. Carbohydr Polym 2005; 62: 142-58.

[223] Wang R, Neoh KG, Shi Z, Kang ET, Tambyah PA, Chiong E. Inhibition of Escherichia coli and Proteus mirabilis adhesion and biofilm formation on medical grade silicone surface. Biotechnol Bioeng 2012; 109(2): 336-45.

[224] Yang JM, Lin HT, Wu TH, Chen C-C. Wettability and antibacterial assessment of chitosan containing radiation-induced graft nonwoven fabric of polypropylene-g-acrylic acid. J Appl Polym Sci 2003; 90: 1331-6.

[225] Ferreira AM, Carmagnola I, Chiono V, et al. Surface modification of poly (dimethylsiloxane) by two-step plasma treatment for further grafting with chitosan-Rose Bengal photosensitizer. Surf Coat Tech 2013; 223: 92-7.

[226] Vo D-T, Whiteley CG, Lee C-K. Hydrophobically modified chitosan-grafted magnetic nanoparticles for bacteria removal. Ind Eng Chem Res 2015; 54: 9270-7. 